\title{
Spaced training improves learning in Ts65Dn and Ube3a mouse models of intellectual disabilities
}

\author{
J. C. Lauterborn ${ }^{1}$, M. N. Schultz ${ }^{2}$, A. A. Le ${ }^{1}$, M. Amani ${ }^{3,4}$, A. E. Friedmann 2,5 P. T. Leach ${ }^{2,6}$, C. M. Gall1', G. S. Lynch ${ }^{1,3}$ and \\ J. N. Crawley $^{2}$
}

\begin{abstract}
Benefits of distributed learning strategies have been extensively described in the human literature, but minimally investigated in intellectual disability syndromes. We tested the hypothesis that training trials spaced apart in time could improve learning in two distinct genetic mouse models of neurodevelopmental disorders characterized by intellectual impairments. As compared to training with massed trials, spaced training significantly improved learning in both the Ts65Dn trisomy mouse model of Down syndrome and the maternally inherited Ube3a mutant mouse model of Angelman syndrome. Spacing the training trials at $1 \mathrm{~h}$ intervals accelerated acquisition of three cognitive tasks by Ts65Dn mice: (1) object location memory, (2) novel object recognition, (3) water maze spatial learning. Further, (4) spaced training improved water maze spatial learning by Ube3a mice. In contrast, (5) cerebellar-mediated rotarod motor learning was not improved by spaced training. Corroborations in three assays, conducted in two model systems, replicated within and across two laboratories, confirm the strength of the findings. Our results indicate strong translational relevance of a behavioral intervention strategy for improving the standard of care in treating the learning difficulties that are characteristic and clinically intractable features of many neurodevelopmental disorders.
\end{abstract}

\section{Introduction}

As first recognized in the late 19th century ${ }^{1}$, and subsequently confirmed by a very large body of human studies $^{2-10}$, multiple training episodes spaced apart in time produce better learning than a single massed session. This spaced trials or distributed practice effect is ubiquitous in that it is observed in many species and across a very broad range of learning paradigms ${ }^{11-28}$. Psychologists have advanced several ingenious theories to explain this fundamental aspect of learning, each of which has received experimental support. One of the most widely discussed of these hypotheses begins with environmental changes

\footnotetext{
Correspondence: J. N. Crawley (crawley@ucdavis.edu)

${ }^{1}$ Department of Anatomy \& Neurobiology, School of Medicine, University of California Irvine, Irvine, CA 92697, USA

${ }^{2}$ MIND Institute, Department of Psychiatry and Behavioral Sciences, University of California Davis School of Medicine, Sacramento, CA 95817, USA Full list of author information is available at the end of the article. These authors contributed equally: J. C. Lauterborn, M. N. Schultz
}

over time and posits that spacing results in the association of core information with multiple contexts. This results in a greater number of retrieval cues and a reduced likelihood that core elements will become associated with transient aspects of the environment ${ }^{29-32}$. An alternative and also highly regarded hypothesis is based on the evidence that memories gradually stabilize with time. These retrieval theories argue that spacing is effective because successive sampling periods add to partially consolidated memory traces ${ }^{33-35}$. An important variant of this idea proposes that distributed learning allows for rehearsal of newly consolidated memory, something that would not happen with massed sessions because the original memory traces are still active ${ }^{4}$. It is possible that no single mechanism accounts for the extreme diversity of spaced trials effects and that the above proposals, with their multiple variants, apply to different aspects of the phenomenon. 
While little is known about the possible contributions of synaptic plasticity rules to the efficacy of spacing, recent work on LTP in hippocampal field CA1 has provided evidence potentially related to consolidation models. Specifically, attempts to produce additional potentiation were unsuccessful when applied at 10-40 min after the initial induction of LTP but doubled the magnitude of the effect when delayed by $50-60 \mathrm{~min}^{21}$. Other experiments found that a previously undetected second stage of consolidation for LTP emerges after the same interval ${ }^{36}$. Mechanisms underlying both the enhanced LTP and the delayed stabilization were described ${ }^{37}$. Work using a type of learning that is dependent on field CA1 then confirmed the behavioral relevance of the LTP results ${ }^{36}$. Whether these effects occur at other forebrain sites possibly with different timing rules has yet to be tested.

Given the ubiquity of the spaced trials effect, and some evidence relating to substrates, it is surprising that little attention has been given to the possibility of using the paradigm to improve learning in various neurodevelopmental disorders with intellectual disabilities. There is however a report suggesting that cue sampling at onehour intervals significantly reduces the learning impairment found in the Fmr1-KO model of Fragile-X syndrome $^{38}$. The present studies tested the generalizability, reproducibility, and robustness of temporally spaced training trials as an intervention for cognitive impairments. We evaluated learning after massed versus spaced training in two genetically distinct mouse models of intellectual disability: (1) the Ts65Dn trisomy model of Down syndrome ${ }^{39-55}$, and (2) the Ube3a maternallyderived knockout model of Angelman syndrome ${ }^{56-64}$. Two laboratories independently tested mice from separate colonies, including comparisons of cohorts bred in-house versus purchased commercially. The generality of any spaced trial benefits across diverse cognitive assays ${ }^{65}$ was evaluated using four learning and memory tasks, with different sensory and motor requirements and different neuroanatomical substrates. Our laboratories ${ }^{38,60,64,66}$ and others cited above had previously demonstrated that these tests detect significant impairments in mouse models of neurodevelopmental disorders including Down and Angelman syndromes. In all, a combination of animal models, testing sites, and behavioral paradigms was used to strengthen conclusions about the potential benefits of spaced training for offsetting cognitive problems associated with aberrant brain development.

\section{Materials and methods \\ Mice}

All studies were approved by the University of California Irvine and University of California Davis Institutional Animal Care and Use Committees, using procedures consistent with the NIH Guide for the Care and Use of Laboratory Animals. Mice were purchased from The Jackson Laboratory and bred as described below. At both facilities, housing cages were maintained in AAALAC-approved temperature and humidity controlled vivaria on a conventional 12:12 light cycle, with lights on at $7 \mathrm{AM}$ and behavioral testing conducted during the light phase of the circadian cycle, between 8 $\mathrm{AM}$ and $5 \mathrm{PM}$. Food and water were provided ad libitum. Mice were 7-14 weeks of age during testing. Object location memory in male WT and Ts65Dn mice was conducted at UC Irvine. Novel object recognition, open field activity, rotarod, and Morris water maze were conducted at UC Davis, in that sequence, for male and female WT and Ts65Dn mice. Male and female WT and Ube3a mice were tested at UC Davis in the sequence of open field, rotarod, water maze. Data from males and females were combined in the statistical analyses. Low numbers of males and females per group precluded detection of sex differences. Larger Ns will be needed in future studies to draw rigorous conclusions about potential sex differences in performance between male and female mice of each genotype in these assays.

\section{Breeding}

To generate in-house bred subject mice for the Down syndrome model, female Ts65Dn (JAX \#005252, which do not harbor the retinal degeneration gene), were mated with males of the same background strain, B6eiC3F1 (JAX \#003647), as previously described ${ }^{64}$. To generate in-house bred subject mice for the Angelman syndrome model, in which the mutation is maternally derived, heterozygous female Ube3a mice (JAX catalogue \#016590) were mated with males of the same background strain, C57BL/6J (JAX \#000664), as previously described ${ }^{64}$. Tailsnips were genotyped by TransnetYX (Cordova, TN) for UC Davis studies, or using Jackson Laboratory PCR methods and KAPA2G HS DNA polymerase (Thermo Fisher Scientific \#NC0562625) for UC Irvine studies. Offspring were weaned at 21-25 days of age into cages of 2-4 mice of mixed genotypes, housed by sex. Males and females of each genotype from each litter and post-weaning housing cage were randomly assigned to training condition groups, to reduce potential effects of any differences in maternal care and home cage environments. Coded identification numbers ensured that investigators remained blind to genotype during testing. For both Ts65Dn and Ube3a lines at UC Davis, Cohort 1 was composed of mice purchased from JAX and Cohort 2 was composed of mice bred in-house. Data are presented separately for each of the two Ts65Dn cohorts in the results, to display the similarities in findings from externally purchased versus vivarium-bred mice. 


\section{Behavioral assays}

Four widely studied behavioral paradigms with varying sensory and motor requirements and different neuroanatomical substrates were used in the present studies. These included (1) object location memory ${ }^{38,66-72}$, (2) novel object recognition ${ }^{54,70,71,73-84}$, (3) Morris water maze spatial learning $44,62,64,69,76,77,85-89$, and (4) rotarod motor learning ${ }^{62,64,78,87,90-101}$.

\section{Object location memory}

The object location memory test was conducted using methods previously described ${ }^{38,66}$. Experiments were conducted in a darkened room with overhead lighting (235 lux) directly above the testing chambers. On Days $1-4$, all mice were handled for $10 \mathrm{~min}$ to acclimate them to the investigator and to being removed from their home cage. On Days 5-10, each mouse was habituated to an empty white testing chamber $(30 \times 24 \mathrm{~cm}$ floor; $30 \mathrm{~cm}$ high) for 5 min per day. Familiarization training occurred on Day 11. For massed training, the subject mouse was placed into the chamber with two identical objects (small glass funnels) located along the same wall, each within $\sim 3 \mathrm{~cm}$ of an arena corner. The mouse was allowed to freely explore during the $10 \mathrm{~min}$ training session. $24 \mathrm{~h}$ later, the mouse was reintroduced to the chamber with one object in the original familiar location and the other object placed in the diagonal corner (novel location). During this test phase for object location memory, the mouse was allowed to explore for $5 \mathrm{~min}$, then returned to its home cage. For spaced training, the mouse was similarly placed into the chamber with two identical objects each located along the same wall, each within $\sim 3 \mathrm{~cm}$ of an arena corner. Three familiarization training trials were administered, each $3.3 \mathrm{~min}$ long, with $1 \mathrm{~h}$ intervals between trials. The subject mouse was returned to its home cage between trials. $24 \mathrm{~h}$ later, the mouse was tested for object location memory during a 5 min exploration period of the chamber with one of the objects moved to the novel location. All objects and chambers were cleaned following training and testing using $1 \mathrm{X}$ SCOE and dried. Sessions were recorded by an overhead video camera. Locomotor activity was analyzed with Noldus Ethovision software. Time $(t)$ spent in exploratory sniffing of each object was quantified offline from the videotapes by raters who were blind to genotype and training treatment. Mice were scored for time spent exploring each object, when the nose was touching or within $0.5 \mathrm{~cm}$ of the object. Grooming, passing by, or head orientation in another direction were excluded. Total time spent in object exploration was quantified as the combined time interacting with both objects. To assess preferential attention to an object, a discrimination index was calculated as $100 \times\left(t_{\text {novel }}-t_{\text {familiar }}\right) \div\left(t_{\text {novel }}+t_{\text {familiar }}\right)$, with a positive discrimination index representing preference for the novel location.

\section{Novel object recognition}

The novel object recognition test for episodic recognition memory was conducted using methods previously described ${ }^{71,102}$, except for the spaced training protocol described below. On Day 1, each mouse was placed in an empty white plastic testing chamber $(40 \times$ $40 \mathrm{~cm}$ ) and allowed to explore for $30 \mathrm{~min}$ to habituate to the arena. On Day 2, the subject mouse was placed in the same empty arena for a second habituation session of $30 \mathrm{~min}$. On day 3, the subject mouse was placed in the same empty arena for a third habituation session of $10 \mathrm{~min}$. The mouse was removed, and two identical objects were placed in the chamber $\sim 12 \mathrm{~cm}$ from the wall and $\sim 18 \mathrm{~cm}$ apart (familiarization session). Objects used were either two orange cones (Amazon.com), or two green cylindrical magnets (Magneatos, Guide Craft, Amazon.com). For massed training, the mouse was replaced into the arena and allowed to explore the two identical objects for $10 \mathrm{~min}$. After this familiarization session, for massed testing, the subject mouse was removed from the arena and returned to its home cage. For spaced training, the mouse was replaced into the arena with the two identical objects and allowed to explore the test arena for $3.3 \mathrm{~min}$, placed in a holding cage in another room for $1 \mathrm{~h}$, placed back in the arena with the two identical objects for another $3.3 \mathrm{~min}$, returned to the holding cage for $1 \mathrm{~h}$, placed back in the arena with the two identical objects for $3.3 \mathrm{~min}$, and returned to its home cage. After the familiarization sessions, objects were cleaned with a weak Alconox detergent solution, and chambers were cleaned with $70 \%$ ethanol. On day 4, $24 \mathrm{~h}$ after the end of familiarization in both conditions, one identical object and one novel object, i.e., cone and cylinder, were placed into the arena in the same locations. The subject mouse was returned to the arena and allowed to explore both objects for $5 \mathrm{~min}$. Novel object recognition was defined as spending significantly more time sniffing the new object than sniffing the familiar object. The novel objects, cone and cylinder, previously determined to elicit similar amounts of sniffing in control mice, were counterbalanced across subject mice to further prevent object bias. Exploratory activity and time spent sniffing each object were scored by Noldus Ethovision XT software (Wageningen, The Netherlands), using three body point identification to include only sniffing directed toward and within $2 \mathrm{~cm}$ of the object. Discrimination index was calculated as $100 \times\left(t_{\text {novel }}-t_{\text {fa- }}\right.$ miliar) $\div$ (tnovel $+t_{\text {familiar }}$ ), with a positive discrimination index representing preference for the novel object. 


\section{Open field exploratory activity}

Open field locomotion was scored during the $30 \mathrm{~min}$ habituation session on Day 2, as an internal control for general exploratory activity. Open field parameters were automatically videotracked and quantified by Noldus Ethovision XT. Parameters of total distance, horizontal activity, vertical activity, and center time were collected in 5 min time bins and summed for the full session length of $30 \mathrm{~min}$.

\section{Rotarod}

Rotarod motor coordination and balance was tested using an Ugo Basile accelerating mouse rotarod, (Stoelting Co., Wood Dale, Illinois) as previously described ${ }^{64}$. Revolutions per minute (rpm) were set at an initial value of $5 \mathrm{rpm}$, increasing progressively to a maximum of $40 \mathrm{rpm}$ across $5 \mathrm{~min}$. Massed training consisted of 3 trials, with $60 \mathrm{sec}$ intervals between each trial. Spaced training consisted of 3 trials, with $1 \mathrm{~h}$ intervals between each trial, consistent with the timing employed in the other three cognitive tasks. Latency to fall was automatically detected by the equipment and recorded for each trial.

\section{Water maze}

Mice were trained in the hidden platform version of the Morris water maze using methods consistent with standards in the literature and as previously described ${ }^{64,77}$. A $120 \mathrm{~cm}$ circular pool was filled with water $\left(24-25^{\circ} \mathrm{C}\right)$. Crayola liquid non-toxic white paint was added for opacity, to prevent proximal visual detection of the hidden platform. External cues for distal spatial navigation included a computer, large sink, water temperature regulator with yellow hose, a large black $\mathrm{X}$ on one wall, a black and white poster on another wall, and a paper lantern hung from the ceiling. Platform locations and start locations were pseudorandomized. Trials were videorecorded and scored by automated software (Noldus Ethovision XT) for measures including latency to find the hidden platform, total distance traveled, and swim speed. For massed training, each subject mouse was given 4 consecutive trials per day, for 10 days, until the WT control group reached the latency criterion of $15 \mathrm{sec}$ or less to reach the hidden platform. Mice were allowed to remain on the platform for $\sim 15 \mathrm{~s}$ after each trial. After the fourth daily trial, each mouse was placed under an infrared heating lamp to help restore body temperature. For spaced training, each subject mouse was given 4 trials per day with $1 \mathrm{~h}$ between each trial, for 10 days, until the WT control group reached the latency criterion of $15 \mathrm{sec}$ or less to reach the hidden platform. Pilot studies with other daily training regimens had indicated lack of beneficial effects of spaced trials in standard C57BL/6J mice given 2 sets of 2 consecutive trials separated by a $1 \mathrm{~h}$ interval between sets, or 3 trials separated by $1 \mathrm{~h}$ intervals, as compared to 4 continuous massed trials (unpublished studies by Adam Friedman and Prescott Leach). Four daily water maze training trials separated by $1 \mathrm{~h}$ intervals appeared to offer an optimal paradigm to specifically evaluate the effects of spaced training in mouse models of intellectual disabilities. After each training trial, subject mice were allowed to remain on the platform for $\sim 15 \mathrm{~s}$, then placed under an infrared heating lamp to help restore body temperature. Probe trial analysis, to confirm that learning the hidden platform location was accomplished using distal environmental room cues and to evaluate long-term memory of the location of the hidden platform, was conducted at $24 \mathrm{~h}$ after the last training trial. Duration of each probe trial was $60 \mathrm{~s}$. Time spent in each of the four pool quadrants, and number of crossings over the former platform location versus the three analogous imaginary platform locations in the other quadrants, were automatically scored by the Noldus videotracking software.

\section{Statistical analyses}

Object location memory and novel object recognition data were analyzed (a) with paired t-tests, comparing the number of seconds spent sniffing each object within genotype and within training condition, during the familiarization and novel object recognition phases, and (b) with a discrimination index (DI, defined as (seconds spent with novel minus seconds spent with familiar) divided by total time (novel + familiar), as previously described $^{70}$. Locomotor activity associated with the object location memory test was analyzed using One-Way Analysis of Variance followed by Tukey's multiple comparisons post-hoc test in cases of significant ANOVA $F$ values. Open field parameters were compared between genotypes using One-Way Analysis of Variance (ANOVA), followed by Tukey's posthoc in cases of a significant ANOVA F value. Rotarod data were analyzed with Two-Way ANOVA using genotype as a between subjects factor and trial as a within subjects factor. Water maze acquisition parameters were evaluated with a TwoWay Repeated Measures ANOVA followed by Bonferroni posthoc tests in cases of significant ANOVA $F$ values. Water maze probe trial data were evaluated with OneWay ANOVA followed by post-hoc Dunnett's multiple comparisons tests to compare the target location to the other three locations, within genotype and within training condition. Data were analyzed and graphed with GraphPad Prism version 7.

\section{Results}

Figure 1 summarizes performance in the object location memory (OLM) test for the Ts65Dn mouse model of Down syndrome and WT littermate controls in experiments conducted at UC Irvine. Past studies showed that 


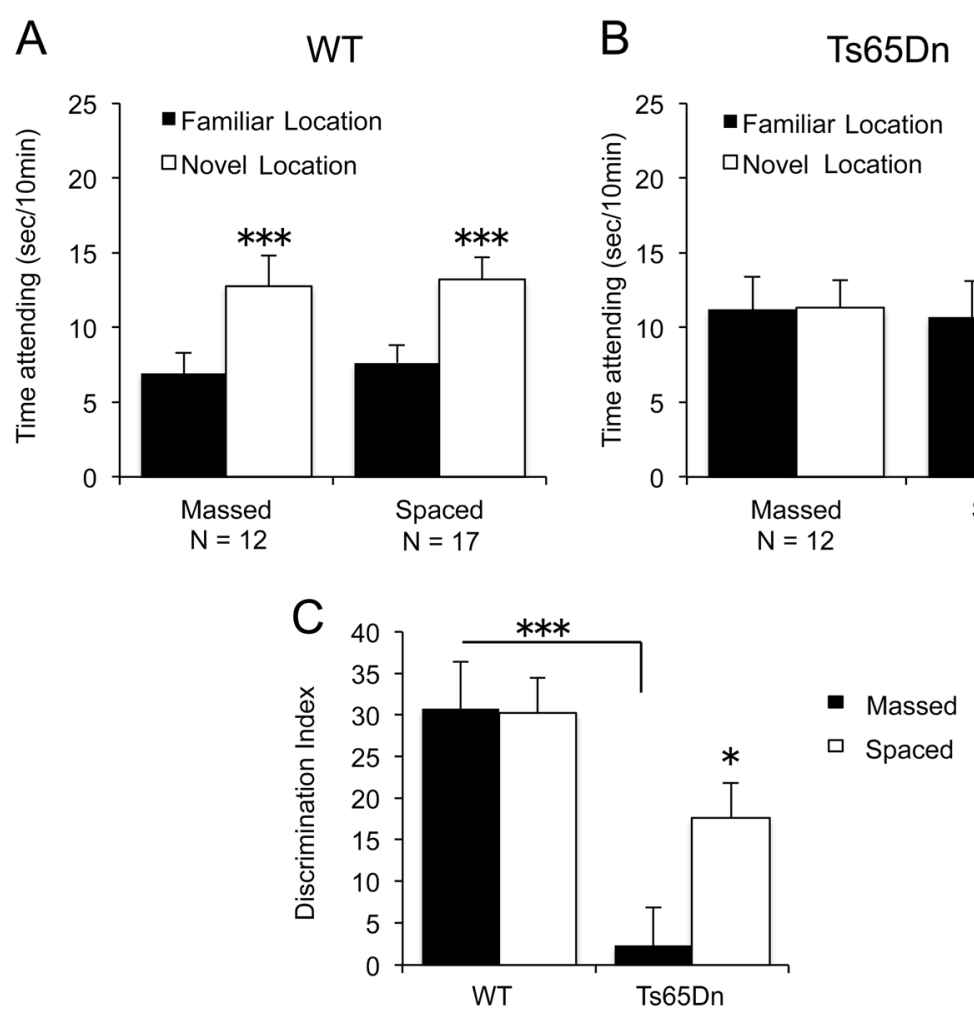

Fig. 1 Object location memory in WT and Ts65Dn mice. Object location memory was detected in WT for both the massed and spaced training conditions. Ts65Dn did not display object location memory in the massed training condition, whereas the spaced training condition yielded significant object location memory. a WT displayed significantly more time exploring the object in the novel location versus the object in the familiar location, both when training trials were administered consecutively (massed: $t_{1,11}=4.66,{ }^{* * *} p<0.001$ ), and when the three training trials were administered at $1 \mathrm{~h}$ intervals (spaced: $t_{1,16}=6.57,{ }^{* *} p<0.001$ ). No effect of training condition alone or of the interaction between training condition and object locations was detected in WT. b Ts65Dn did not display a significant difference between time spent exploring the object in the familiar location and the object in the novel location when training trials were administered consecutively (massed: $t_{1,11}=0.109$, NS). Ts65Dn displayed significantly more time exploring the object in the novel location versus the object in the familiar location when training trials were administered at $1 \mathrm{~h}$ intervals (spaced: $t_{1,11}=3.06, \mathrm{df}_{1,11},{ }^{*} p<0.02$ ). A significant interaction between training conditions and object locations was detected by TwoWay ANOVA for Ts65Dn $(p<0.05)$. c Discrimination index (DI) was lower in Ts65Dn mice given massed training trials as compared to WT given massed training trials $\left.{ }^{* * *} p<0.001\right)$. Spaced training trials significantly elevated the DI in Ts65Dn, as compared to the DI in Ts65Dn given massed training trials $\left({ }^{*} p<0.05\right)$. A significant interaction between genotype and training condition was detected by Two-Way ANOVA $(p<0.05)$. In all figures, data are expressed as mean + standard error of the mean. Numbers of mice in each genotype and training condition group are displayed within the graphs

WT animals acquire memory in this test after a five or ten minute session of unsupervised exposure to the cues ${ }^{103}$. We used a 10-min session to maximize massed trial performance by the mutants. As anticipated, the WT controls had a pronounced preference for the novel location in tests conducted $24 \mathrm{~h}$ after a single massed training period. Spaced exposures to the cues on day one did not increase this high retention score (Fig. 1a, see legends for statistical results). As predicted, Ts65Dn failed to display OLM, showing equivalent numbers of seconds spent exploring the object in the new location and the object in the original location during the retention trial when the familiarization training trials were massed in one 10-min session. In contrast, when familiarization was spaced into 3 training trials, each of $3.3 \mathrm{~min}$ duration, separated by 1 -h intervals, Ts65Dn mice displayed significant OLM (Fig. 1b). Data analysis using the derived discrimination index confirmed that supra-threshold massed training produced no evidence for long-term memory in Ts65Dn, whereas this striking defect was partially prevented by spaced training (Fig. 1c).

The encoding problem found in the Ts65Dn animals during massed training could not be attributed to a failure in cue sampling, since both genotypes spent the same total amount of time exploring the objects during the session and as well in the subsequent retention test (Supplementary Fig. S1a). This was also the case for each of the three spaced trials and the delayed memory measurement (Fig. S1b). Overall exploration of the apparatus during habituation and massed training was also 

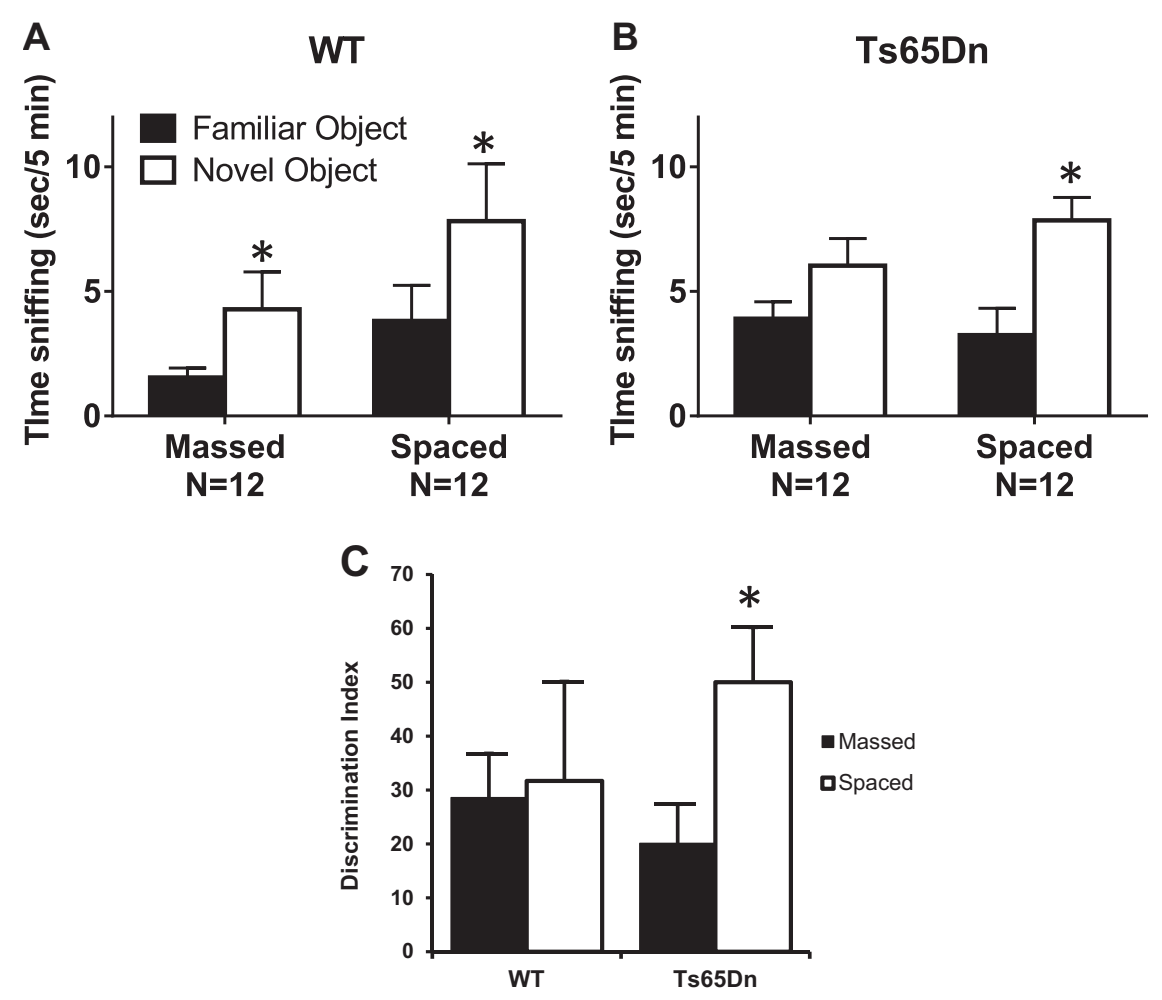

Fig. 2 Novel object recognition in WT and Ts65Dn mice. Novel object recognition memory was detected in WT for both the massed and spaced training conditions. Ts65Dn did not display novel object recognition in the massed training condition, whereas the spaced training condition yielded significant novel object recognition. a WT displayed significantly more time exploring the novel object than the familiar object, both when training trials were administered consecutively (massed: $t_{1,11}=2.29,{ }^{*} p<0.05$ ), and when the three training trials were administered at $1 \mathrm{~h}$ intervals (spaced: $\left.t_{1,10}=2.31,{ }^{*} p<0.05\right)$. b Ts65Dn did not display a significant difference between time spent exploring the novel object and time spent exploring the familiar object (massed: $t_{1,11}=2.035$, NS). Ts65Dn displayed significantly more time exploring the novel object than the familiar object when training trials were administered at $1 \mathrm{~h}$ intervals (spaced: $t_{1,11}=3.60,{ }^{*} p<0.01$ ). c Spaced training trials significantly elevated the DI in Ts65Dn, as compared to the DI in Ts65Dn given massed training trials $\left({ }^{*} p<0.05\right)$. Interaction between genotype and training condition was not significant

comparable between the groups (Fig. S1c). This also held for exploration during the three spaced training sessions (Fig. S1d). Finally, total arena exploration time did not differ between learning protocols or genotypes (Fig. S1e). We conclude from these sampling times and activity measurements that the Ts65Dn mutation did not affect the manner in which the animals interact with simple cues or explore a simple environment, confirming that object location memory scores were not confounded by exploration artifacts.

Figure 2 shows analogous results in Ts65Dn mice tested on novel object recognition, a second recognition learning and memory assay, conducted at UC Davis. We again used an unsupervised sampling period $(10 \mathrm{~min})$ that from past reports ${ }^{38}$ is supra-threshold for learning cue identity in WT mice. Controls spent more time exploring the novel object than the familiar object after both massed and spaced training (Fig. 2a). Ts65Dn showed equivalent numbers of seconds spent sniffing the novel object and the familiar object when the familiarization training trials were massed in one $10 \mathrm{~min}$ session, indicating failure to acquire or remember the object properties. In contrast, when familiarization was spaced into 3 training trials separated by 1-hour intervals, Ts65Dn mice displayed a marked and significant novel object recognition effect (Fig. 2b). Data analyses using the derived discrimination index confirmed that spaced training profoundly enhanced object learning in the mutants (Fig. 2c). As shown in Supplementary Fig. 2, sampling times for the two cues during the acquisition session did not differ between massed and spaced trials for the WTs (Fig. S2a) or mutants (Fig. S2b). There was a tendency for the latter to spend more time with the objects but this did not reach statistical significance. As with the OLM paradigm, amount of general arena exploration did not differ between genotypes (Fig. S2c).

Figure 3 illustrates the deficits in water maze learning in Ts65Dn mice, and presents evidence that these deficits were ameliorated by spaced training trials. Data in Fig. 3 represent one full cohort of WT and Ts65Dn mice, purchased from JAX and housed at UC Davis. WT reached the criterion of $\leq 15 \mathrm{~s}$ to reach the hidden platform after 

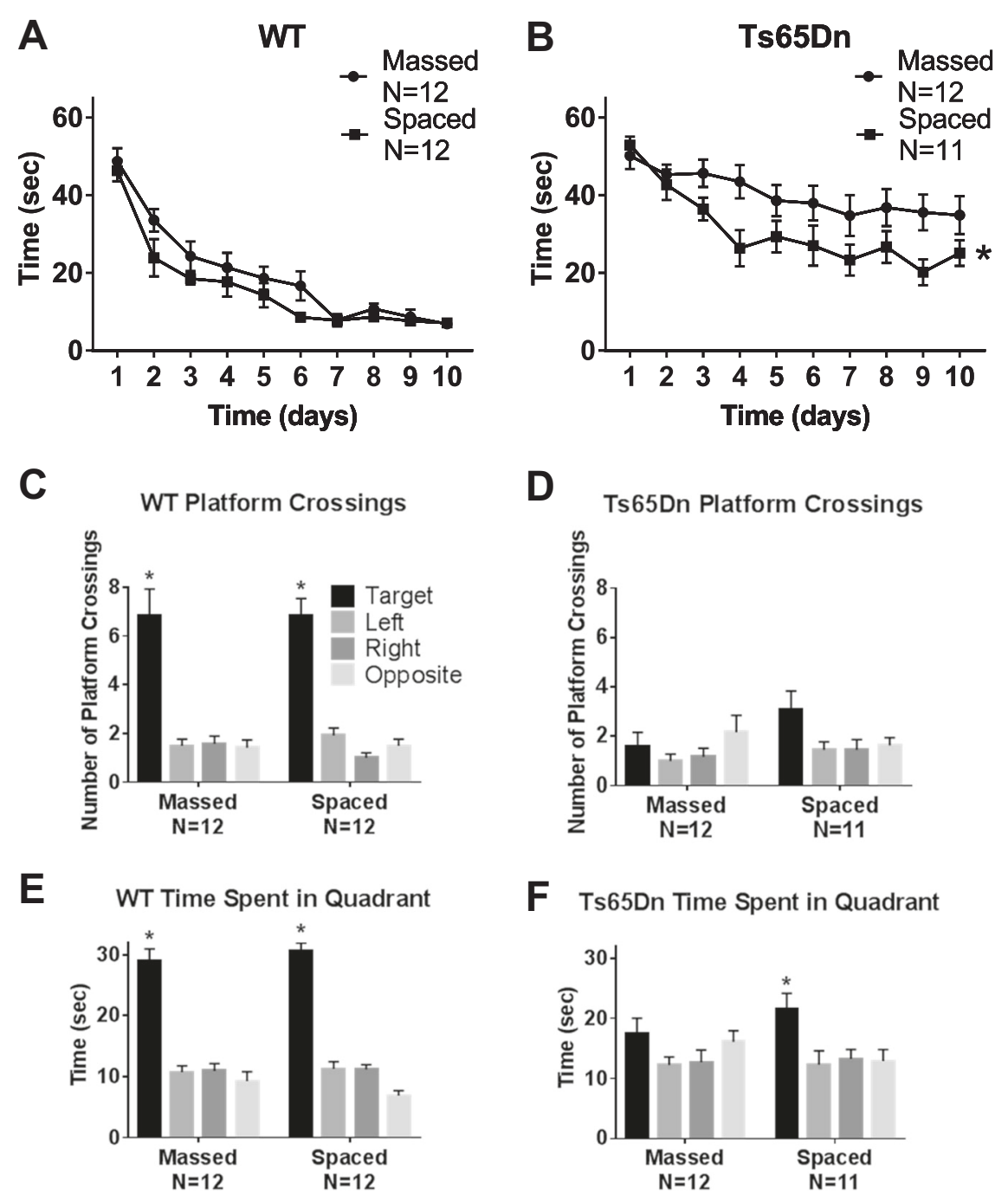

F Ts65Dn Time Spent in Quadrant

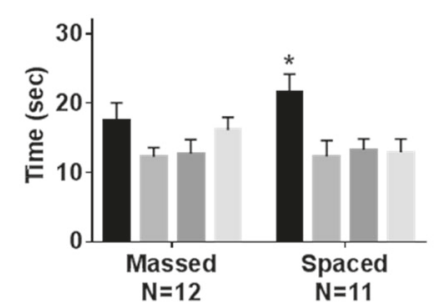

Fig. 3 Morris water maze performance in WT and Ts65Dn mice, Cohort 1. Ts65Dn displayed impaired spatial learning, which was improved by training with distributed trials spaced at $1 \mathrm{~h}$ intervals. a WT successfully achieved the acquisition criterion of $15 \mathrm{~s}$ or less to reach the hidden platform location. No significant difference was detected in the time course for acquisition by WT mice trained with massed versus spaced trials (Two-Way ANOVA $\left.F_{1,23}=0.101, N S\right)$, indicating no faster learning in WT trained with spaced trials. A significant effect of training day was detected in WT $\left(F_{9,207}\right.$ $=18.97, p<0.001$ ), indicating learning across days as expected. No significant interaction between massed versus spaced $\mathrm{x}$ training day was detected in WT $\left(F_{9,207}=0.410, N S\right)$. $\mathbf{b}$ Ts65Dn trained with massed trials did not achieve the acquisition criterion of $15 \mathrm{~s}$ or less to reach the hidden platform location. A significant difference was detected in the time course for acquisition by Ts65Dn mice trained with massed versus spaced trials $\left(F_{1,24}=\right.$ $\left.8.064,{ }^{*} p<0.001\right)$, indicating faster learning with spaced training trials. A significant effect of training day was detected $\left(F_{9,216}=5.99, p<0.001\right)$, indicating some learning across training days. No significant interaction between massed versus spaced $x$ training day was detected in Ts65Dn $\left(F_{9,216}\right.$ $=1.02$, NS). $\mathbf{c}-\mathbf{f}$ Probe trial performance $24 \mathrm{~h}$ after the last training trial. $\mathbf{c W T}$ crossed the previously trained target platform location significantly more times than over the corresponding left, right, and opposite locations, in both the massed and spaced training conditions (massed: $F_{3,44}=19.52,{ }^{*} p<$ 0.001; Dunnett's multiple comparisons adjusted $p$ values: target vs. left $p<0.001$, target vs. right $p<0.001$, target vs. opposite $p<0.001 ;$ spaced: $F_{3,44}$ $=41.33,{ }^{*} p<0.001$; target vs. left $p<0.001$, target vs. right $p<0.0001$, target vs. opposite $p<0.0001$ ). $\mathbf{d}$ Ts65Dn did not cross the previously trained target platform location significantly more than the corresponding left, right, and opposite locations, in either the massed or spaced training conditions, although a trend was seen after spaced training (massed: $F_{3,44}=1.096$, NS; spaced: $F_{3,40}=2.739, p=0.06$, NS). e WT spent more time in the previously trained target quadrant than in the left, right, and opposite quadrants, for both massed and spaced training groups (massed: $F_{3,44}=$ $41.72,{ }^{*} p<0.001$; target vs. left $p<0.001$, target vs. right $p<0.001$, target vs. opposite $p<0.001$; spaced: $F_{3,44}=104.6,{ }^{*} p<0.001$; target vs. left $p<$ 0.001 , target vs. right $p<0.001$, target vs. opposite $p<0.001$ ). f Ts65Dn spent significantly more time in the previously trained target quadrant than in the left, right, and opposite quadrants after spaced training but not in the massed training condition (massed: $F_{3,44}=1.597, \mathrm{NS} ;$ spaced: $F_{3.40}=4.289$, ${ }^{*} p<0.01$; target vs. left $p<0.01$, target vs. right $p<0.05$, target vs. opposite $p<0.05$ ) 
seven days of training, both when the four training trials were massed consecutively and when the four trials were separated by $1 \mathrm{~h}$ intervals. Ts65Dn failed to reach criterion in both conditions, but performance, defined as reduction in time to locate the hidden platform across training days, was significantly better when the four training trials were spaced by $1 \mathrm{~h}$ intervals rather than massed. In the spaced training condition, Ts65Dn displayed decreasing latencies during the first 4 days of training, but no further improvement across days 5-10. In contrast, WT in the spaced training condition displayed latencies which decreased through training day 7 , and remain below criterion through day 10 . These results suggest that mice with the Ts65Dn mutation have some capacity for spatial learning, particularly when training trials are temporally spaced, but may not have abilities sufficient to reach the same performance asymptote as controls, at least in the present paradigm. Probe trial analysis $24 \mathrm{~h}$ after the last training trial confirmed that WT mice had learned the hidden platform location using distal spatial room cues and remembered the hidden platform location one day later. WT made more crossings over the previous platform location than the corresponding locations in each of the other three quadrants, and spent more time swimming in the quadrant that previously contained the hidden platform than in the other three quadrants. These results were obtained in both the massed and spaced training conditions. Ts65Dn did not make significantly more crossings over the previous platform location in either training condition. Equivocal findings were obtained for time spent in the trained quadrant. Ts65Dn in the spaced training group spent significantly more time swimming in the previously trained quadrant than in the other three quadrants, while the massed training group did not. However, number of seconds spent in the trained quadrant was very similar in Ts65Dn trained with massed and spaced trials. Supplementary Fig. 3a,b confirms that initial swim speeds were similar between genotypes, indicating normal motor swimming abilities in Ts65Dn mice. The acquisition curve results support the interpretation that spaced training improved spatial learning in Ts65Dn mice, although performance levels reached by WT were not fully achieved by Ts65Dn.

Figure 4 summarizes water maze learning results in a second cohort of Ts65Dn mice, which was bred in-house at UC Davis. Again, WT reached criterion both in the massed and spaced training conditions. Ts65Dn failed to reach criterion in either condition, but performance was significantly better when the four training trials were spaced by $1 \mathrm{~h}$ intervals as compared to massed. Probe trial analysis $24 \mathrm{~h}$ after the last training trial confirmed that WT had learned and remembered the hidden platform location, on measures of platform location crossings and quadrant time, in both the massed and spaced training conditions. Ts65Dn that received massed training failed to display significantly more crossings over the previous platform location, and did not spend more time in the previously trained quadrant in the massed condition. Ts65Dn that received spaced training showed significantly more crossings over the previous platform location and significantly more time swimming in the previously trained quadrant. However, number of seconds spent in the trained quadrant was similar in Ts65Dn after massed and spaced training. Supplementary Fig. 3c,d confirms that initial swim speeds were similar between genotypes, indicating normal motor swimming abilities in the second cohort of Ts65Dn mice. These acquisition curves in cohort 2 corroborate the interpretation that spaced training improved spatial learning in Ts65Dn mice, although WT performance levels were not reached. Replicated findings in two full cohorts, one purchased directly from JAX and one bred in-house, confirm the strength of the water maze results.

Next, we tested whether the training paradigm results described above extend to a mouse model for a different neurodevelopmental disorder, Angelman syndrome. Figure 5 describes the deficits in water maze learning in Ube3a mice and improvements by spaced training trials. WT reached criterion both in the massed and spaced training conditions. Ube3a failed to reach criterion in either condition, but performance was significantly better when the four training trials were spaced by $1 \mathrm{~h}$ intervals than when massed consecutively. Probe trial analysis $24 \mathrm{~h}$ after the last training trial confirmed that WT had learned the platform location using distal spatial room cues and remembered the former platform location, on measures of platform location crossings and quadrant time, in both the massed and spaced training conditions. Ube $3 a$ failed to display significantly more crossings over the previous platform location in the massed training condition, but achieved significance in the spaced training condition. Ube3a spent significantly more time swimming in the previously trained quadrant in both the massed and spaced conditions, with approximately the same numbers of seconds spent in the trained quadrant for both conditions. Supplementary Fig. 3e,f displays impaired swim speeds in Ube3a as compared to WT in the massed group. Higher swim speeds in the Ube3a spaced group were seen during the initial training days, raising the possibility of motor improvement as an alternate explanation for the learning curve. However, the magnitude of swim speed improvement was relatively small. Data in Fig. 5 represent one full cohort of WT and Ube $3 a$ mice purchased from JAX and tested at UC Davis. Poor in-house breeding success of Ube3a at UC Davis prevented the generation of a second full cohort for corroborative testing. 

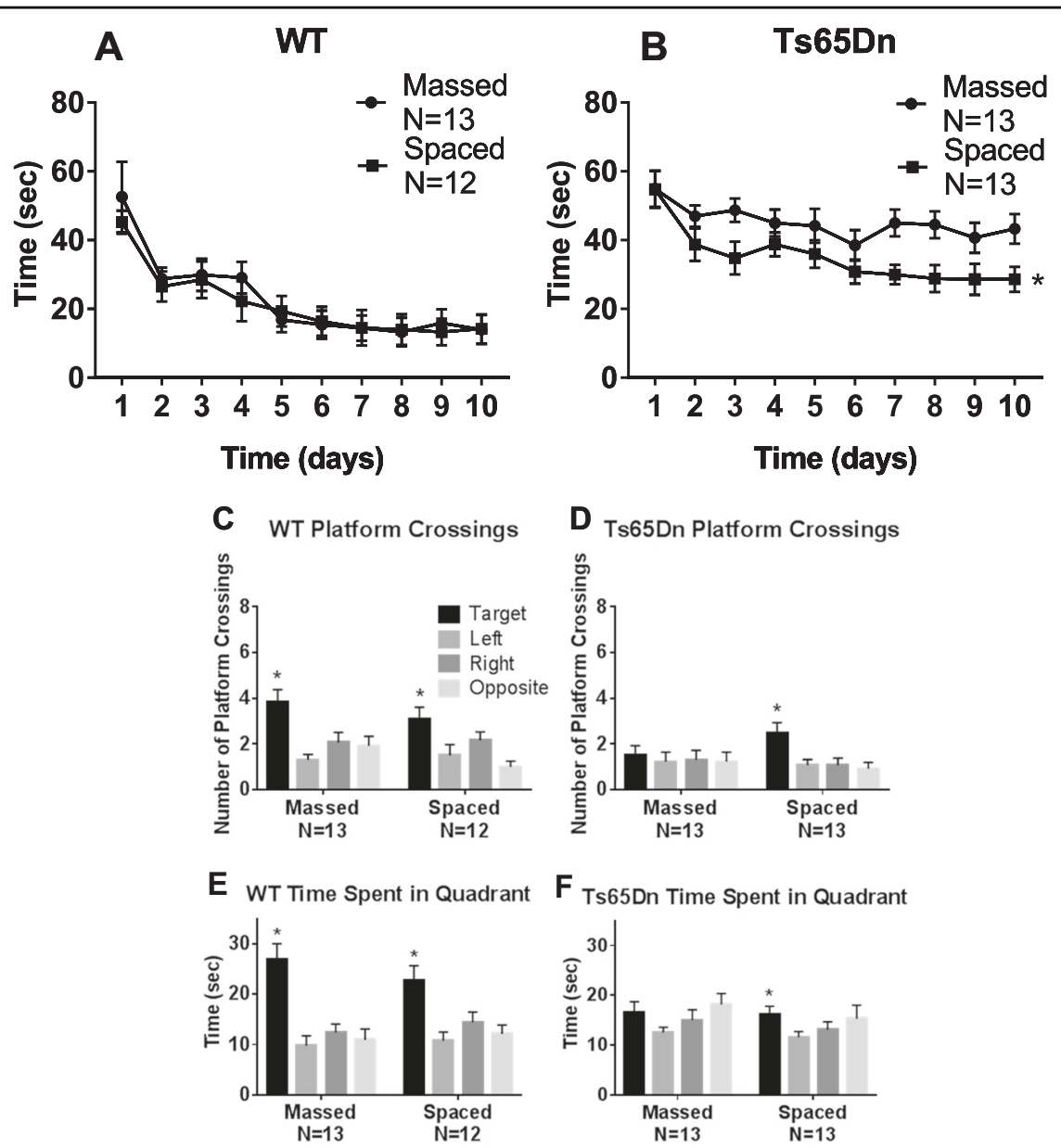

Fig. 4 Morris water maze performance in WT and Ts65Dn mice, Cohort 2 replication. As seen in Cohort 1, a second independent cohort of Ts65Dn similarly displayed impaired spatial learning which was improved by training with distributed trials spaced at $1 \mathrm{~h}$ intervals. a WT successfully achieved the acquisition criterion of $15 \mathrm{~s}$ or less to reach the hidden platform location. No significance was detected in the time course for acquisition by WT mice trained with massed versus spaced trials $\left(F_{1,23}=0.110, \mathrm{NS}\right)$, indicating no faster learning in WT trained with spaced trials. A significant effect of training day was detected in WT $\left(F_{9,207}=19.0, p<0.001\right)$, indicating learning across days as expected. No significant interaction between massed versus spaced $x$ training day was detected in WT $\left(F_{9,207}=0.410, N S\right)$. $\mathbf{b}$ Ts65Dn did not achieve the acquisition criteria of $15 \mathrm{~s}$ or less to reach the hidden platform location. A significant difference was detected in the time course for acquisition by Ts65Dn mice trained with massed versus spaced trials $\left(F_{1,24}=8.06,{ }^{*} p<0.01\right)$, indicating faster learning with spaced training trials. A significant effect of training day was detected $\left(F_{9,216}=\right.$ $5.60, p<0.001$ ), indicating some learning across training days. No significant interaction between massed versus spaced $\mathrm{x}$ training day was detected in Ts65Dn ( $F_{9,216}=1.02$, NS). Three-way ANOVA detected significance for latency $\left(F_{1,9}=23.1, p<0.001\right)$, genotype $\left(F_{1,1}=35.8, p<0.001\right)$, no significance for latency $x$ treatment $\left(F_{1,9}=0.295, \mathrm{NS}\right)$, or latency $\mathrm{x}$ genotype $\mathrm{x}$ treatment $\left(F_{1,9}=1.11, \mathrm{NS}\right)$. $\mathbf{c}-\mathbf{f}$ Probe trial performance $24 \mathrm{~h}$ after the last training trial. c WT crossed the previously trained target platform location significantly more than over the corresponding left, right, and opposite locations, in both the massed and spaced training conditions (massed: $F_{3,48}=6.85,{ }^{*} p<0.001$; Dunnett's multiple comparisons adjusted $p$ values: target vs. left $p<0.001$, target vs. right $p<0.05$, target vs. opposite $p<0.01$; spaced: $F_{3,44}=4.681$, ${ }^{*} p<0.01$; target vs. left $p<0.05$, target vs. opposite $p<0.01$. $\mathbf{d}$ Ts65Dn crossed the previously trained target platform location significantly more than the corresponding left, right, and opposite locations, after spaced training but not after massed training trials (massed: $F_{3,48}=0.129$, NS, spaced: $F_{3,48}=4.64,{ }^{*} p<0.01$; target vs. left $p<0.05$, target vs. right $p<0.05$, target vs. opposite $p<0.01$ ). e WT spent more time in the previously trained target quadrant than in the left, right, and opposite quadrants, for both massed versus spaced training groups (massed: $F_{3,48}=12.5,{ }^{*} p<0.001$; target vs. left $p<0.001$, target vs. right $p<0.001$, target vs. opposite $p<0.001$; spaced: $F_{3,44}=6.45,{ }^{*} p<0.001$; target vs. left $p<0.001$, target vs. right $p<0.05$, target vs. opposite $p<0.01$ ). f Ts65Dn spent more time in the previously trained target quadrant than in the left, right, and opposite quadrants, after spaced training but not after massed training trials (massed: $F_{3,48}=2.32$, NS; spaced: $F_{3,48}=3.39,{ }^{*} p<0.05$; target vs. left $p<0.05$, target vs. right $p<0.05$ )

Figure 6 shows that rotarod motor learning in Ts65Dn and Ube3a mice was similar when the three daily training trials were massed consecutively or separated by $1 \mathrm{~h}$ intervals. Ts65Dn of both cohorts showed no significant deficits, displaying rotarod performance that was not different than WT controls, and not significantly different between training conditions. Ube3a displayed impaired rotarod performance as previously reported ${ }^{42,62,64}$, seen as 

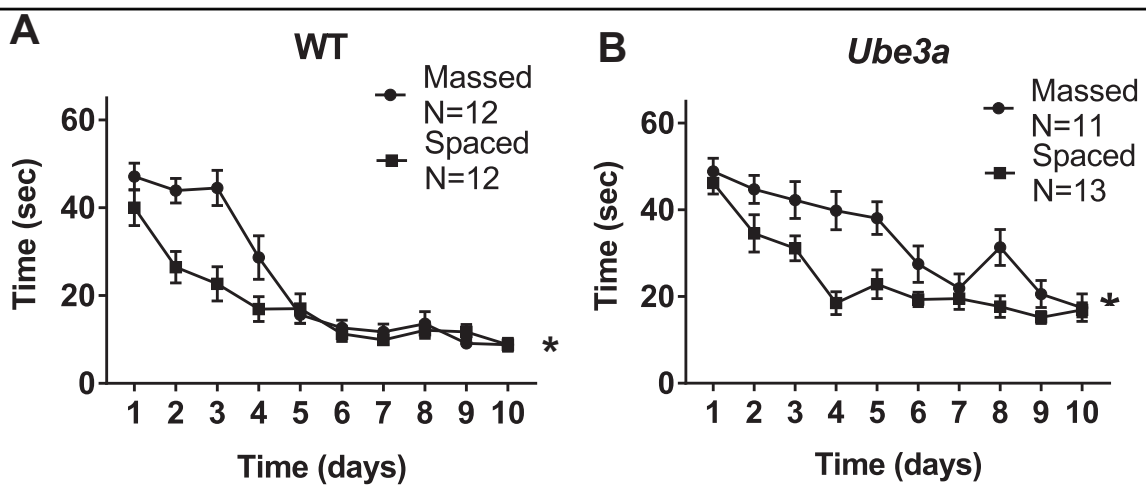

C
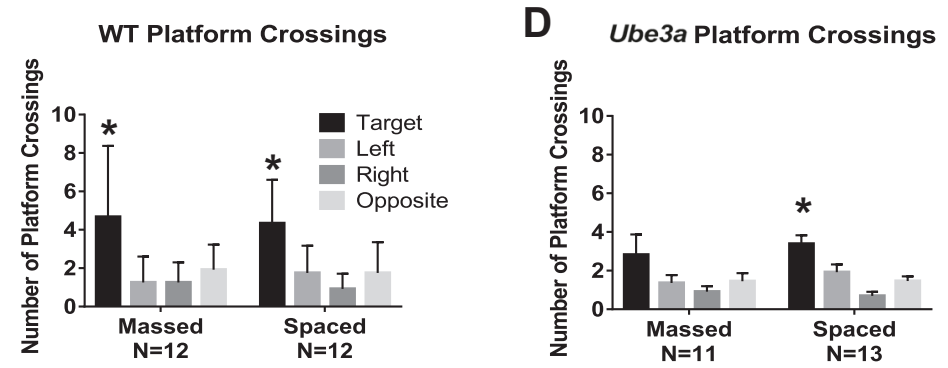

E

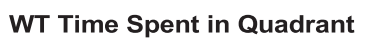

\section{$\mathbf{F}$}
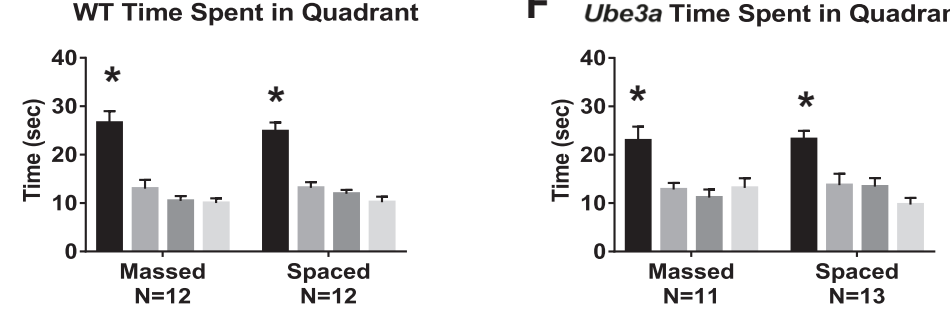

Fig. 5 Morris water maze performance in WT and Ube3a mice. Ube3a displayed impaired spatial learning, which was improved by training with distributed trials spaced at $1 \mathrm{~h}$ intervals. a WT successfully achieved the acquisition criterion of $15 \mathrm{~s}$ or less to reach the hidden platform location. A significant difference was detected in the time course for acquisition by WT mice trained with massed versus spaced trials $\left(F_{1,22}=8.47,{ }^{*} p<0.01\right)$, indicating faster learning in WT trained with spaced trials. A significant effect of training day was detected in $W T\left(F_{9,198}=49.3, p<0.001\right)$, indicating learning across days as expected. A significant interaction between massed versus spaced $x$ training day was detected in $W T,\left(F_{9,198}=5.62, p<0.001\right)$. b Ube 3 a did not achieve the acquisition criterion of $15 \mathrm{~s}$ or less to reach the hidden platform location. A significant difference was detected in the time course for acquisition by Ube3a mice trained with massed versus spaced trials $\left(F_{1,22}=15.8,{ }^{*} p<0.001\right)$, indicating faster learning with spaced training trials. A significant effect of training day was detected $\left(F_{9,198}=24.6, p<0.01\right)$, indicating some learning across training days. A significant interaction between massed versus spaced $x$ training day was detected in Ube3a $\left(F_{9,198}=2.65, p<0.01\right)$. Three-way ANOVA detected significance for latency $\left(F_{1,9}=68.9, p<0.001\right.$, latency $\times$ training condition: $F_{1,9}=5.16, p<0.001$, latency $\times$ genotype $\times$ training condition: $\left.F_{1,9}=2.74, p<0.01\right)$. c-e Probe trial performance $24 \mathrm{~h}$ after the last training trial. c WT crossed the previously trained target platform location significantly more times than over the corresponding left, right, and opposite locations, in both the massed and spaced training conditions (massed: $F_{3,44}=6.92,{ }^{*} p<0.001$; Dunnett's multiple comparisons adjusted $p$ values: target vs. left $p<0.001$, target vs. right $p<0.001$, target vs. opposite $p<0.01 ;$ spaced: $F_{3,44}=10.2$, ${ }^{*} p<0.001$, Dunnett's multiple comparisons adjusted $p$ values: target vs. left $p<0.001$, target vs. right $p<0.001$, target vs. opposite $p<0.001$. d Ube3a crossed the previously trained target platform location significantly more than the left, right, and opposite corresponding platform locations after spaced training trials, but not after massed training trials (massed: $F_{4,42}=1.69$, NS; spaced: $F_{3,48}=11.1,{ }^{*} p<0.001$; target vs. left $p<0.01$, target vs. right $p<0.001$, target vs. opposite $p<0.001$ ). e WT spent significantly more time in the previously trained target quadrant than in the left, right, and opposite quadrants, for both massed versus spaced (massed: $F_{3,44}=22.3,{ }^{*} p<0.001$; target vs. left $p<0.001$, target vs. right $p<0.001$, target vs. opposite $p<0.001$; spaced: $F_{3,44}=26.4,{ }^{*} p<0.001$; target vs. left $p<0.001$, target vs. right $p<0.001$, target vs. opposite $p<0.001$ ). f Ube3a spent significantly more time in the previously trained target quadrant than in the left, right, and opposite quadrants, for both massed versus spaced (massed: $F_{3,40}=6.73,{ }^{*} p<0.001$; target vs. left $p<0.01$, target vs. right $p<0.001$, target vs. opposite $p<0.01$; spaced: $F_{3,48}=9.74,{ }^{*} p<0.001$; target vs. left $p<0.01$, target vs. right $p<0.01$, target vs. opposite $p<0.001$ )

shorter latencies to fall from the accelerating rotating rod as compared to WT. Spaced training did not significantly improve rotarod performance as compared to massed training in Ube3a.

\section{Discussion}

The present studies investigated the possibility that spaced training can be used as a general strategy for treating the learning problems that are a characteristic 


\section{Ts65Dn Cohort 1}
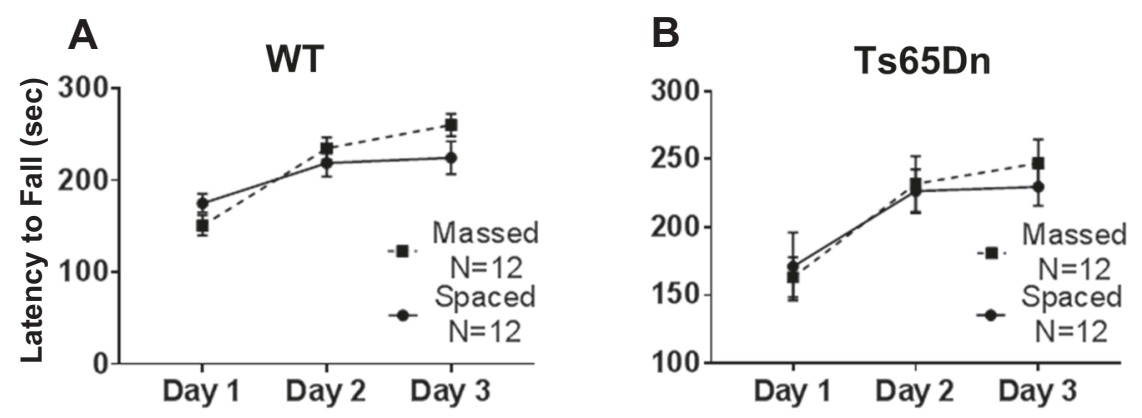

\section{Ts65Dn Cohort 2}
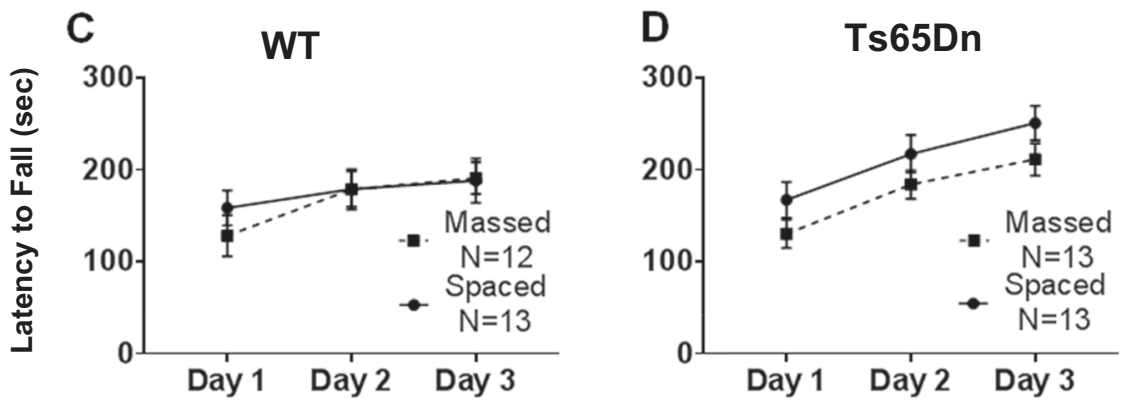

\section{$\underline{\text { Ube3a }}$}
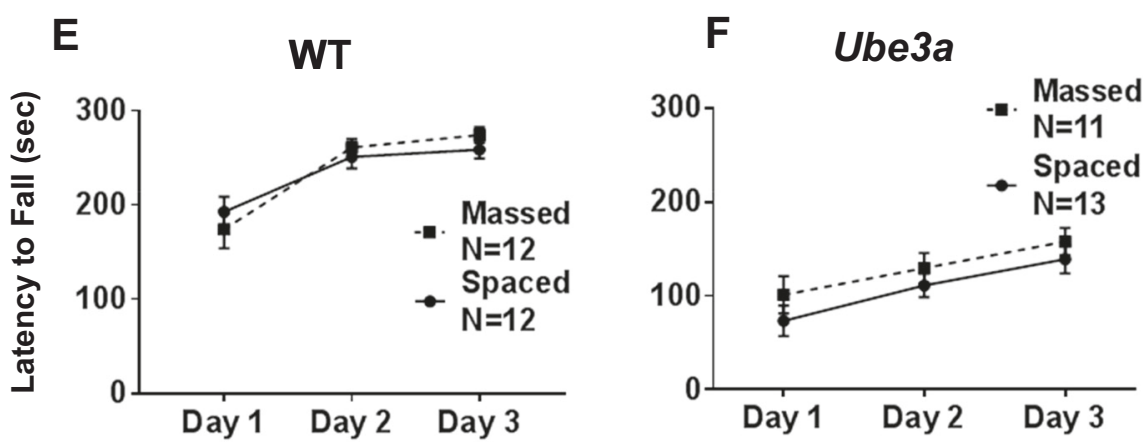

Fig. 6 Rotarod motor learning was unaffected by training condition in either Ts65Dn or Ube3a mice. a-d Ts65Dn mice were not significantly impaired on rotarod performance, as measured by latency to fall from the accelerating rotarod, when compared to WT controls (Cohort $1: F_{1,1}=$ 0.0037, NS; Cohort 2: $\left.F_{1,1}=1.57, \mathrm{NS}\right)$. a Cohort $1 \mathrm{WT}$ displayed similar motor learning curves when trained with massed versus spaced trials $\left(F_{1,22}=\right.$ 0.336 , NS). WT showed a significant effect of training day $\left(F_{2,44}=45.8, p<0.0001\right)$, and a significant interaction between massed versus spaced $x$ training day $\left(F_{2,44}=6.03, p<0.01\right)$. b Cohort 1 Ts65Dn displayed similar motor learning curves when trained with massed versus spaced trials $\left(F_{1,22}=\right.$ 0.05 , NS). Ts65Dn showed a significant effect of training day $\left(F_{2,44}=23.2, p<0.001\right)$, but no interaction between massed versus spaced $x$ training day $\left(F_{2,44}=0.613, N S\right)$. c Cohort 2 WT displayed similar motor learning curves when trained with massed versus spaced trials $\left(F_{1,23}=0.112, \mathrm{NS}\right)$. WT showed a significant effect of training day $\left(F_{2,46}=15.6, p<0.001\right)$, but no interaction between massed versus spaced $\times$ training day $\left(F_{2,46}=2.24\right.$, NS). d Cohort 2 Ts65Dn displayed similar motor learning curves when trained with massed versus spaced trials $\left(F_{1,24}=2.30, \mathrm{NS}\right)$. Ts65Dn showed a significant effect of training day $\left(F_{2,48}=84.1, p<0.001\right)$, but no interaction between massed versus spaced $x$ training day $\left(F_{2,48}=0.116\right.$, NS). e-f $U$ be3a mice were significantly impaired on rotarod motor learning as compared to WT controls $\left(F_{1,1}=118.6, p<0.001\right)$. e WT displayed similar motor learning curves when trained with massed versus spaced trials $\left(F_{1,22}=0.044, \mathrm{NS}\right)$. WT showed a significant effect of training day $\left(F_{2,44}=25.2\right.$, $p<$ $0.001)$, but no interaction between massed versus spaced $x$ training day $\left(F_{2,44}=1.02, N S\right)$. $\mathbf{f}$ Ube3a displayed similar motor learning curves when trained with massed versus spaced trials $\left(F_{1,22}=1.47, \mathrm{NS}\right)$. Ube3a showed a significant effect of training day $\left(F_{2,44}=11.8, p<0.001\right)$, but no interaction between massed versus spaced $x$ training day $\left(F_{2,44}=0.0874, \mathrm{NS}\right)$

and clinically intractable feature of many neurodevelopmental disorders (NDD). A useful therapy would have to be applicable to a number of these conditions and, equally important, have beneficial effects across multiple commonplace forms of learning. The findings reported here satisfy these criteria. Spacing training improved learning 
on tests for encoding of both semantic (cue identity) and spatial information in two mutant mouse models, and in paradigms that did or did not include strong motivation. Notably, although improved performance did not reach fully normal levels on spatial learning, the improvements in recognition and spatial learning tasks occurred against a background of severe learning impairments in animals trained with massed trials. The results were also robust in that they obtained in different laboratories and across separate cohorts of mice. Relatedly, a prior study found marked improvements with spacing in a mouse model for a third neurodevelopmental disorder, Fragile $\mathrm{X}$ syndrome $^{38}$, strengthening generalizability across mouse models of three neurodevelopmental disorders with intellectual disabilities.

What types of mechanisms could be responsible for these observations, or more specifically, how does the spacing protocol offset NDD-related disturbances to brain systems for acquiring and utilizing information? Imaging studies in children and adults with these disorders have revealed altered functional connectivity in brain activation patterns, unusual density of white matter tracts, altered cortical thickness, microencephaly and macroencephaly, depending on the genetic mutation ${ }^{104-108}$. Unusual patterns of neuronal dendritic spine morphology have been reported in human postmortem analyses ${ }^{109-112}$. A large number of studies detected analogous abnormalities in dendritic spine morphology in mutant mouse models of neurodevelopmental disorders with intellectual disabilities $^{43,50,78,111,113-120}$. As might be expected from spine aberrations, substantial impairments in the memoryrelated LTP effect are multiply reported for Ts65Dn, Ube3a, and Fmr1-KO mice ${ }^{103,117-122}$. In each of these cases, significant progress has been made in identifying defects in the signaling cascades responsible for the stabilization of synaptic potentiation (Ts65Dn: ${ }^{123-125}$, Ube3a: ${ }^{60,126,127}$, Fmr1-KO: $\left.{ }^{119,122,128,129}\right)$. Moreover, and of considerable interest in the present context, various experimental pharmacological interventions are reported to reduce the magnitude of the LTP deficit and the accompanying learning problems ${ }^{48,59,60,121,130-140}$. In all, while it is unlikely that spacing affects the profound morphological disturbances that characterize the NDD brain, it is possible that the protocol in some manner compensates for defects in the complex machinery that produces plasticity.

Consistent with the above argument, a recent study found that Fmr1 knockout mice fail to activate an LTPcritical enzyme at hippocampal synapses when given a single learning episode and that this signaling deficit is reduced with trials separated by the minimal interval $(1 \mathrm{~h})$ for the "LTP spaced trial" effect ${ }^{38}$. We therefore propose that (i) many NDDs cause breaks in the sequences that consolidate one trial LTP and learning, as described above, and (ii) the events that produce secondary potentiation after a delay are sufficiently intact to produce a net increase in memory-related synaptic strength. The latter part of this argument is testable with procedures used to describe the cell biological substrates for the delayed LTP effect $^{21}$.

While spacing was effective in three of the behavioral paradigms, it produced no evident reductions in the impairments to motor learning on the accelerating rotarod. We found no difference between three massed training trials on each of three training days versus three training trials spaced at one-hour intervals on each of three training days. Ube3a displayed its previously reported deficit on rotarod performance, which was not improved by spaced training. Rotarod motor learning is mediated primarily by the cerebellum ${ }^{87,141-143}$, while acquisition in the water maze $\mathrm{144-147}^{67,6 \text { object }}$ location $^{68,148-150}$, and novel object $^{67,68,151,152}$ recognition paradigms are heavily dependent upon structures in the cortical telencephalon. It is reasonable to expect that memory encoding substrates may differ significantly between cerebellar vs. forebrain networks; if so, then the between trials delay used here may not have been appropriate for eliciting spacing effects of the type previously reported for motor learning, ${ }^{5,153}$. In any event, the absence of effects in the rotarod task is consistent with the idea that the positive results for spatial and semantic memory reflect activation of LTP-related processes described for hippocampus.

Finally, the present results suggest opportunities for potential clinical applications. Direct comparisons of massed versus spaced training sessions have not been published in the human literature for either Down syndrome or Angelman syndrome. A small number of studies have been published for children with genetically unspecified intellectual impairments. This sparse literature reported better performance after spaced training trials for a transfer task ${ }^{154}$ and better performance after spaced trials on the initial phase of learning a motor skill in one study $^{155}$, although no effect of spaced sessions on motor learning was seen in three other studies ${ }^{156-158}$, consistent with our findings of no differences on rotarod motor learning between massed versus spaced training regimens in Ts65Dn and Ube3a mice. In small studies of autism spectrum disorder, spaced practice sessions were more effective than massed practice sessions on syllable learning in three children with autism spectrum disorder ${ }^{159}$, while massed training was more effective than spaced on a pictorial task in six children with autism ${ }^{160}$. It will be interesting to investigate spaced versus massed learning approaches across a range of cognitive tests in children, adolescents and adults with various genetically defined intellectual disability syndromes ${ }^{137,161-168}$. The present findings in the Ts65Dn trisomy mouse model of Down syndrome and the Ube3a maternally-derived mutant 
mouse model of Angelman syndrome, along with our previous parallel findings in the Fmr1 mutant mouse model of Fragile $\mathrm{X}$ syndrome ${ }^{38}$, support the strategy of therapeutic behavioral interventions using spaced sessions of distributed learning opportunities, to enhance cognitive abilities in neurodevelopmental disorders characterized by intellectual disabilities.

\section{Acknowledgements}

Supported by R01NS085709 (JNC, CMG, GL), U54HD079125 (JNC),

R21HD079823 (JCL), and the University of California Irvine Center for Autism Research and Treatment.

\section{Author details}

${ }^{1}$ Department of Anatomy \& Neurobiology, School of Medicine, University of California Irvine, Irvine, CA 92697, USA. ${ }^{2}$ MIND Institute, Department of Psychiatry and Behavioral Sciences, University of California Davis School of Medicine, Sacramento, CA 95817, USA. ${ }^{3}$ Department of Psychiatry and Human Behavior, School of Medicine, University of California Irvine, Irvine, CA 92697, USA. ${ }^{4}$ Department of Physiology, School of Medicine, Ardabil University of Medical Sciences, Ardabil, Iran. ${ }^{5}$ Present address: Harvard University, Cambridge, MA, USA. ${ }^{6}$ Present address: Biogen Inc., Cambridge, MA, USA

\section{Authors' contributions}

J.C.L., M.N.S., and A.L. conducted the experiments, analyzed the data, and prepared the figures and legends. P.T.L. and A.E.F. conducted initial experiments with B6 and Ts65Dn mice on water maze spaced learning protocols. J.N.C., C.M.G., and G.S.L. conceived the project, designed the experiments, supervised procedures, and wrote the manuscript.

\section{Conflict of interest}

The authors declare that they have no conflict of interest.

\section{Publisher's note}

Springer Nature remains neutral with regard to jurisdictional claims in published maps and institutional affiliations.

Supplementary Information accompanies this paper at (https://doi.org/ 10.1038/s41398-019-0495-5).

Received: 3 December 2018 Revised: 14 March 2019 Accepted: 23 March 2019

Published online: 10 June 2019

\section{References}

1. Ebbinghaus, H. Über das Gedächtnis. Untersuchungen zur experimentellen Psychologie (Memory: A Contribution to Experimental Psychology) (1885).

2. Estes, W. K. Statistical theory of distributional phenomena in learning. Psychol. Rev. 62, 369-377 (1955).

3. Crowder, R. G. Principles of Learning and Memory. (Erlbaum, Hillsdale, NJ, 1976).

4. Greene, R. L. Spacing effects in memory: Evidence for a two-process account. J. Exp. Psychol.: Learn., Mem., Cogn. 15, 371-377 (1989).

5. Shea, C. H., Lai, Q., Black, C. \& Park, J. H. Spacing practice sessions across days benefits the learning of motor skills. Hum. Mov. Sci. 19, 737-760 (2000).

6. Goverover, Y., Arango-Lasprilla, J. C., Hillary, F. G., Chiaravalloti, N. \& Deluca, J. Application of the spacing effect to improve learning and memory for functional tasks in traumatic brain injury: a pilot study. Am. J. Occup. Ther. 63 , 543-548 (2009).

7. Kornell, N., Castel, A. D., Eich, T. S. \& Bjork, R. A. Spacing as the friend of both memory and induction in young and older adults. Psychol. Aging $\mathbf{2 5}$ 498-503 (2010).

8. Callan, D. E. \& Schweighofer, N. Neural correlates of the spacing effect in explicit verbal semantic encoding support the deficient-processing theory. Hum. Brain Mapp. 31, 645-659 (2010).
9. Vlach, H. A. \& Sandhofer, C. M. Distributing learning over time: the spacing effect in children's acquisition and generalization of science concepts. Child Dev. 83, 1137-1144 (2012).

10. Jackson, C. E., Maruff, P. T. \& Snyder, P. J. Massed versus spaced visuospatial memory in cognitively healthy young and older adults. Alzheimers Dement. $\mathbf{9}$ S32-S38 (2013).

11. McGaugh, J. L. Time-dependent processes in memory storage. Science $\mathbf{1 5 3}$, 1351-1358 (1966).

12. Goodrick, C. L. Maze learning of mature-young and aged rats as a function of distribution of practice. J. Exp. Psychol. 98, 344-349 (1973).

13. Kogan, J. H. et al. Spaced training induces normal long-term memory in CREB mutant mice. Curr. Biol. 7, 1-11 (1997).

14. Klapdor, K. \& Van Der Staay, F. J. Repeated acquisition of a spatial navigation task in mice: effects of spacing of trials and of unilateral middle cerebral artery occlusion. Physiol. Behav. 63, 903-909 (1998).

15. Mauelshagen, J., Sherff, C. M. \& Carew, T. J. Differential induction of longterm synaptic facilitation by spaced and massed applications of serotonin at sensory neuron synapses of Aplysia californica. Learn Mem. 5, 246-256 (1998).

16. Beck, C. D., Schroeder, B. \& Davis, R. L. Learning performance of normal and mutant Drosophila after repeated conditioning trials with discrete stimuli. $J$ Neurosci. 20, 2944-2953 (2000).

17. Scharf, M. T. et al. Protein synthesis is required for the enhancement of longterm potentiation and long-term memory by spaced training. J. Neurophysiol. 87, 2770-2777 (2002).

18. Bolding, K. \& Rudy, J. W. Place learning in the Morris water task: Making the memory stick. Learn. Mem. 13, 278-286 (2006).

19. Sisti, H. M., Glass, A. L. \& Shors, T. J. Neurogenesis and the spacing effect: learning over time enhances memory and the survival of new neurons. Learn Mem. 14, 368-375 (2007).

20. Anderson, M. J., Jablonski, S. A. \& Klimas, D. B. Spaced initial stimulus familiarization enhances novelty preference in Long-Evans rats. Behav. Process. 78 481-486 (2008).

21. Kramár, E. A. et al. Synaptic evidence for the efficacy of spaced learning. Proc. Natl. Acad. Sci. USA 27, 5121-5126 (2012).

22. Philips, G. T., Kopec, A. M. \& Carew, T. J. Pattern and predictability in memory formation: from molecular mechanisms to clinical relevance. Neurobiol. Learn Mem. 105, 117-124 (2013).

23. Aziz, W. et al. Distinct kinetics of synaptic structural plasticity, memory formation, and memory decay in massed and spaced learning. Proc. Natl. Acad. Sci. USA 111, E194-E202 (2014).

24. Wingard, J. C., Goodman, J., Leong, K. C. \& Packard, M. G. Differential effects of massed and spaced training on place and response learning: A memory systems perspective. Behav. Process. 118, 85-89 (2015).

25. Barrientos, R. M. et al. Stable, long-term, spatial memory in young and aged rats achieved with a one day Morris water maze training protocol. Learn. Mem. 23, 699-702 (2016)

26. San Martin, A., Rela, L., Gelb, B. \& Pagani, M. R. The spacing effect for structural synaptic plasticity provides specificity and precision in plastic changes. $J$. Neurosci. 37, 4992-5007 (2017).

27. Nonaka, M. et al. Everyday memory: towards a translationally effective method of modelling the encoding, forgetting and enhancement of memory. Eur. J. Neurosci. 46, 1937-1953 (2017).

28. Stern, S. A., Doerig, K. R., Azevedo, E. P., Stoffel, E., Friedman, J. M. Control of non-homeostatic feeding in sated mice using associative learning of contextual food cues. Mol. Psychiatry. 2018. https://doi.org/10.1038/s41380-018$0072-y$.

29. Madigan, S. A. Intraserial repetition and coding processes in free recall. J. Verb. Learn. Verb. Behav. 8, 828-835 (1969).

30. Melton, A. W. The situation with respect to the spacing of repetitions and memory. J. Verb. Learn. Verb. Behav. 9, 596-606 (1970).

31. Benjamin, A. S. \& Tullis, J. What makes distributed practice effective? Cogn Psychol 61, 228-247 (2010)

32. Siegel, L. L. \& Kahana, M. J. A retrieved context account of spacing and repetition effects in free recall. J. Exp. Psychol. Learn. Mem. Cogn. 40, 755-776 (2014).

33. Landauer, T. K. Reinforcement as consolidation. Psychol. Rev. 76, 82-96 (1969).

34. Wickelgren, W. A. Trace resistance and the decay of long-term memory. J. Math. Psychol. 9, 418-455 (1972).

35. Toppino, T. C. \& Bloom, L. C. The spacing effect, free recall, and two-process theory: a closer look. J. Exp. Psychol. Learn. Mem. Cogn. 28, 437-444 (2002). 
36. Babayan, A. H. et al. Integrin dynamics produce a delayed stage of LTP and memory consolidation. J. Neurosci. 32, 12854-12861 (2012).

37. Lynch, G., Kramar, E. A., Babayan, A. H., Rumbaugh, G. \& Gall, C. M. Differences between synaptic plasticity thresholds result in new timing rules for maximizing long-term potentiation. Neuropharmacology 64, 27-36 (2013).

38. Seese, R. R., Wang, K., Yao, Y. Q., Lynch, G. \& Gall, C. M. Spaced training rescues memory and ERK1/2 signaling in fragile $\mathrm{X}$ syndrome model mice. Proc. Natl. Acad. Sci. USA 111, 16907-16912 (2014b).

39. Reeves, R. H. et al. A mouse model for Down syndrome exhibits learning and behaviour deficits. Nat. Genet. 11, 177-184 (1995).

40. Coussons-Read, M. E. \& Crnic, L. S. Behavioral assessment of the Ts65Dn mouse, a model for Down syndrome: altered behavior in the elevated plus maze and open field. Behav. Genet. 26, 7-13 (1996).

41. Reeves, R. Down syndrome mouse models are looking up. Trends Mol. Med. 12, 237-240 (2006)

42. van Woerden, G. M. et al. Rescue of neurological deficits in a mouse model for Angelman syndrome by reduction of alphaCaMKIl inhibitory phosphorylation. Nat. Neurosci. 10, 280-282 (2007).

43. Belichenko, P. V., Kleschevnikov, A. M., Salehi, A., Epstein, C. J. \& Mobley, W. C. Synaptic and cognitive abnormalities in mouse models of Down syndrome: exploring genotype-phenotype relationships. J. Comp. Neurol. 504, 329-345 (2007).

44. Olson, L. E. et al. Trisomy for the Down syndrome 'critical region' is necessary but not sufficient for brain phenotypes of trisomic mice. Hum. Mol. Genet. 16, 774-782 (2007).

45. Costa, A. C. S., Stasko, M. R., Schmidt, C. \& Davisson, M. T. Behavioral validation of the Ts65Dn mouse model for Down syndrome of a genetic background free of the retinal degeneration mutation Pde6r ${ }^{\text {rdl }}$. Behav. Brain Res. 206, $52-62$ (2010).

46. Gardiner, K. et al. Down syndrome: from understanding the neurobiology to therapy. J. Neuroscience 30, 14943-14945 (2010).

47. Daily, J., Smith, A. G. \& Weeber, E. J. Spatial and temporal silencing of the human maternal UBE3A gene. Eur. J. Paediatr. Neurol. 16, 587-591 (2012).

48. Kleschevnikov, A. M. et al. Deficits in cognition and synaptic plasticity in a mouse model of Down syndrome ameliorated by $G A B A_{B}$ receptor agonists. J. Neurosci. 32, 9217-9227 (2012).

49. Mohler, H. Cognitive enhancement by pharmacological and behavioral interventions: the murine Down syndrome model. Biochem. Pharmacol. 84, 994-999 (2012).

50. Cramer, N. \& Galdzicki, Z. From abnormal hippocampal synaptic plasticity in Down syndrome mouse models to cognitive disability in Down syndrome. Neural Plast. 2012, 101542 (2012).

51. Martínez-Cué, C., Delatour, B. \& Potier, M. C. Treating enhanced GABAergic inhibition in Down syndrome: use of GABA a5-selective inverse agonists. Neurosci. Biobehav Rev. 46, 218-227 (2014).

52. Dutka, T., Hallberg, D. \& Reeves, R. H. Chronic up-regulation of the SHH pathway normalizes some developmental effects of trisomy in Ts65Dn mice. Mech. Dev. 135, 68-80 (2015).

53. Olmos-Serrano, J. L., Tyler, W. A., Cabral, H. J. \& Haydar, T. F. Longitudinal measures of cognition in the Ts65Dn mouse: Refining windows and defining modalities for therapeutic intervention in Down syndrome. Exp. Neurol. 279, 40-56 (2016).

54. Kleschevnikov, A. M. et al. Evidence that increased Kcnj6 gene dose is necessary for deficits in behavior and dentate gyrus synaptic plasticity in the Ts65Dn mouse model of Down syndrome. Neurobiol. Dis. 103, 1-10 (2017).

55. Godfrey, M. \& Lee, N. R. Memory profiles in Down syndrome across development: a review of memory abilities through the lifespan. J. Neurodev. Disord. 10, 5 (2018).

56. Jiang, Y., Lev-Lehman, E., Bressler, J., Tsai, T. F. \& Beaudet, A. L. Genetics of Angelman syndrome. Am. J. Hum. Genet. 65, 1-6 (1999).

57. Heck, D. H., Zhao, Y., Roy, S., LeDoux, M. S. \& Reiter, L. T. Analysis of cerebellar function in Ube3a-deficient mice reveals novel genotype-specific behaviors. Hum. Mol. Genet. 17, 2181-2189 (2008).

58. Jiang, Y. H. et al. Altered ultrasonic vocalization and impaired learning and memory in Angelman syndrome mouse model with a large maternal deletion from Ube3a to Gabrb3. PloS ONE 5, e12278 (2010).

59. Mabb, A. M., Judson, M. C., Zylka, M. J. \& Philpot, B. D. Angelman syndrome: insights into genomic imprinting and neurodevelopmental phenotypes. Trends Neurosci. 34, 293-303 (2011).
60. Baudry, M. et al. Ampakines promote spine actin polymerization, long-term potentiation, and learning in a mouse model of Angelman syndrome. Neurobiol. Dis. 47, 210-215 (2012).

61. Kaphzan, H. et al. Reversal of impaired hippocampal long-term potentiation and contextual fear memory deficits in Angelman syndrome model mice by ErbB inhibitors. Biol. Psychiatry 72, 182-190 (2012).

62. Huang, H. S. et al. Behavioral deficits in an Angelman syndrome model: effects of genetic background and age. Behav. Brain Res. 243, 79-90 (2013).

63. Santini, E. et al. Reducing elF4E-elF4G interactions restores the balance between protein synthesis and actin dynamics in fragile $\mathrm{X}$ syndrome model mice. Sci. Signal. 10, 504 (2017).

64. Leach, P. T. \& Crawley, J. N. Touchscreen learning deficits in Ube3a, Ts65Dn and Mecp2 mouse models of neurodevelopmental disorders with intellectual disabilities. Genes, Brain Behav. 17, e12452 (2018).

65. Gyertyan, I. Cognitive "Omics": Pattern-based validation of potential drug targets. Trends Pharmacol. Sci. 38, 113-126 (2017).

66. Seese, R. R., Maske, A. R., Lynch, G. \& Gall, C. M. Long-term memory deficits are associated with elevated synaptic ERK1/2 activation and reversed by mGluR5 antagonism in an animal model of autism. Neuropsychopharmacology 39, 1664-1673 (2014a)

67. Kesner, R. P., Bolland, B. L. \& Dakis, M. Memory for spatial locations, motor responses, and objects: triple dissociation among the hippocampus, caudate nucleus, and extrastriate visual cortex. Exp. Brain Res. 93, 462-470 (1993).

68. Dere, E., Huston, J. P., De Souza \& Silva, M. A. The pharmacology, neuroanatomy and neurogenetics of one-trial object recognition in rodents. Neurosci. Biobehav Rev. 31, 673-704 (2007).

69. Hunsaker, M. R., Wenzel, H. J., Willemsen, R. \& Berman, R. F. Progressive spatial processing deficits in a mouse model of the fragile $X$ premutation. Behav. Neurosci. 123, 1315-1324 (2009).

70. Vogel-Ciernia, A. \& Wood, M. A. Examining object location and object recognition memory in mice. Curr. Protoc. Neurosci. 69, 1-17 (2014).

71. Yang, M., Lewis, F. C., Sarvi, M. S., Foley, G. M. \& Crawley, J. N. 16p11.2 Deletion mice display cognitive deficits in touchscreen learning and novelty recognition tasks. Learn. Mem. 22, 622-632 (2015).

72. Li, W. et al. A small-molecule TrkB ligand restores hippocampal synaptic plasticity and object location memory in Rett syndrome mice. Dis. Model Mech. 10, 837-845 (2017).

73. Ennaceur, A. \& Delacour, J. A new one-trial test for neurobiological studies of memory in rats. 1: Behavioral data. Behav. Brain Res. 31, 47-59 (1988).

74. Miyakawa, T. et al. Neurogranin null mutant mice display performance deficits on spatial learning tasks with anxiety related components. Hippocampus 11, 763-775 (2001).

75. Wrenn, C. C. et al. Galanin peptide levels in hippocampus and cortex of galanin-overexpressing transgenic mice evaluated for cognitive performance. Neuropeptides 36, 413-426 (2002).

76. Faizi, M. et al. Comprehensive behavioral phenotyping of Ts65Dn mouse model of Down syndrome: activation of $\beta 1$-adrenergic receptor by xamoterol as a potential cognitive enhancer. Neurobiol. Dis. 43, 397-413 (2011).

77. Brielmaier, J. et al. Autism-relevant social abnormalities and cognitive deficits in engrailed-2 knockout mice. PLOS ONE 7, e40914 (2012).

78. Yang, $M$. et al. Reduced excitatory neurotransmission and mild autismrelevant phenotypes in adolescent Shank3 null mutant mice. J. Neuroscience 32, 6525-6541 (2012).

79. Leger, M. et al. Object recognition test in mice. Nat. Protoc. 8, 2531-2537 (2013).

80. Silverman, J. L., Oliver, C. F., Karras, M. N., Gastrell, P. T. \& Crawley, J. N. AMPAKINE enhancement of social interaction in the BTBR mouse model of autism. Neuropharmacology 64, 268-282 (2013).

81. Lipina, T. V. \& Roder, J. C. Co-learning facilitates memory in mice: a new avenue in social neuroscience. Neuropharmacology 64, 283-293 (2013).

82. Flannery, B. M. et al. Behavioral assessment of $\mathrm{NIH}$ Swiss mice acutely intoxicated with tetramethylenedisulfotetramine. Neurotoxicol Teratol. 47, 36-45 (2015).

83. Hall, J. H. et al. Tc1 mouse model of trisomy-21 dissociates properties of short- and long-term recognition memory. Neurobiol. Learn Mem. 130, 118-128 (2016).

84. Gulinello, M. et al. Rigor and reproducibility in rodent behavioral research. Neurobiol. Learn Mem. 2018. https://doi.org/10.1016/.j.nlm.2018.01.001.

85. Morris, R. G., Anderson, E., Lynch, G. S. \& Baudry, M. Selective impairment of learning and blockade of long-term potentiation by an N-methyl-D-aspartate receptor antagonist, AP5. Nature 319, 774-776 (1986). 
86. Moran, T. H. et al. The effects of piracetam on cognitive performance in a mouse model of Down's syndrome. Physiol. Behav. 77, 403-409 (2002).

87. Tsai, P. T. et al. Autistic-like behaviour and cerebellar dysfunction in Purkinje cell Tsc1 mutant mice. Nature 488, 647-651 (2012).

88. Provenzano, G., Pangrazzi, L., Poli, A., Berardi, N. \& Bozzi, Y. Immunohistochemical visualization of hippocampal neuron activity after spatial learning in a mouse model of neurodevelopmental disorders. J. Vis. Exp. 99, e52919 (2015).

89. Wurzman, R., Forcelli, P. A., Griffey, C. J. \& Kromer, L. F. Repetitive grooming and sensorimotor abnormalities in an ephrin-A knockout model for autism spectrum disorders. Behav. Brain Res. 278, 115-128 (2015).

90. Costa, A. C., Walsh, K. \& Davisson, M. T. Motor dysfunction in a mouse model of Down syndrome. Physiol. Behav. 68, 211-220 (1999).

91. Paylor, R. et al. Impaired learning and motor behavior in heterozygous Pafah1b1 (Lis1) mutant mice. Learn. Mem. 6, 521-537 (1999).

92. Ey, E. et al. Absence of deficits in social behaviors and ultrasonic vocalizations in later generations of mice lacking neuroligin4. Genes Brain Behav. 11, 928-941 (2012).

93. Baxter, L. L., Moran, T. H., Richtsmeier, J. T., Troncoso, J. \& Reeves, R. H. Discovery and genetic localization of Down syndrome cerebellar phenotypes using the Ts65Dn mouse. Hum. Mol. Genet. 9, 195-202 (2000).

94. Hyde, L. A., Crnic, L. S., Pollock, A. \& Bickford, P. C. Motor learning in Ts65Dn mice, a model for Down syndrome. Dev. Psychobiol. 38, 33-45 (2001).

95. Holmes, A., Yang, R. J., Murphy, D. L. \& Crawley, J. N. Evaluation of antidepressant-related behavioral responses in mice lacking the serotonin transporter. Neuropsychopharmacology 27, 914-923 (2002).

96. Lalonde, R., Le Pêcheur, M., Strazielle, C. \& London, J. Exploratory activity and motor coordination in wild-type SOD1/SOD1 transgenic mice. Brain Res. Bull. 66, 155-162 (2005)

97. Abramow-Newerly, W. et al. Methods to rapidly and accurately screen a large number of ENU mutagenized mice for abnormal motor phenotypes. Amyotroph. Lateral Scler. 7, 112-118 (2006).

98. Chadman, K. K. et al. Minimal aberrant behavioral phenotypes of neuroligin-3 R451C knockin mice. Autism. Research 1, 147-158 (2008).

99. Thompson, B. L. \& Levitt, P. Complete or partial reduction of the Met receptor tyrosine kinase in distinct circuits differentially impacts mouse behavior. J. Neurodev. Disord. 7, 35 (2015).

100. Shevelkin, A. V. et al. Expression of mutant DISC1 in Purkinje cells increases their spontaneous activity and impairs cognitive and social behaviors in mice. Neurobiol. Dis. 103, 144-153 (2017).

101. Cairns, J. et al. Abnormalities in the structure and function of cerebellar neurons and neuroglia in the LC/+chimeric mouse model of variable developmental Purkinje cell loss. Cerebellum 16, 40-54 (2017).

102. Dhamne, S. C. et al. Replicable in vivo physiological and behavioral phenotypes of the Shank3B null mutant mouse model of autism. Mol. Autism 8, 26 (2017).

103. Seese, R. R. et al. LTP induction translocates cortactin at distant synapses in wild-type but not Fmr1 knock-out mice. J. Neurosci. 32, 7403-7413 (2012).

104. Lainhart, J. E. Brain imaging research in autism spectrum disorders: in search of neuropathology and health across the lifespan. Curr. Opin. Psychiatry 28, 76-82 (2015).

105. Wilson, P. H. et al. Cognitive and neuroimaging findings in developmental coordination disorder: new insights from a systematic review of recent research. Dev. Med Child Neurol. 59, 1117-1129 (2017).

106. Klein, M., van Donkelaar, M., Verhoef, E. \& Franke, B. Imaging genetics in neurodevelopmental psychopathology. Am. J. Med Genet. B Neuropsychiatr. Genet. 174, 485-537 (2017).

107. Neale, N., Padilla, C., Fonseca, L. M., Holland, T. \& Zaman, S. Neuroimaging and other modalities to assess Alzheimer's disease in Down syndrome. Neuroimage Clin. 17, 263-271 (2017).

108. Jack, A. Neuroimaging in neurodevelopmental disorders: focus on restingstate fMRI analysis of intrinsic functional brain connectivity. Curr. Opin. Neurol. 31, 140-148 (2018)

109. Purpura, D. P. Spine dysgenesis and mental retardation. Science $\mathbf{8 0}$, 1126-1128 (1974).

110. Irwin, S. A. et al. Abnormal dendritic spine characteristics in the temporal and visual cortices of patients with fragile-X syndrome: a quantitative examination. Am. J. Med Genet. 98, 161-167 (2001).

111. Phillips, M. \& Pozzo-Miller, L. Dendritic spine dysgenesis in autism related disorders. Neurosci. Lett. 601, 30-40 (2015).
112. Torres, M. D., Garcia, O., Tang, C. \& Busciglio, J. Dendritic spine pathology and thrombospondin-1 deficits in Down syndrome. Free Radic. Biol. Med. 114 10-14 (2018).

113. Baudouin, S. J. et al. Shared synaptic pathophysiology in syndromic and nonsyndromic rodent models of autism. Science 338, 128-132 (2012).

114. Lauterborn, J. C., Jafari, M., Babayan, A. H. \& Gall, C. M. Environmental enrichment reveals effects of genotype on hippocampal spine morphologies in the mouse model of Fragile X Syndrome. Cereb. Cortex 25, 516-527 (2015).

115. Santini, E. et al. Mitochondrial superoxide contributes to hippocampal synaptic dysfunction and memory deficits in Angelman syndrome mode mice. J. Neuroscience 35, 16213-16220 (2015).

116. Washbourne, P. Synapse assembly and neurodevelopmental disorders. Neuropsychopharmacology 40, 4-15 (2015).

117. Yi, J. J. et al. An autism-linked mutation disables phosphorylation control of UBE3A. Cell 162, 795-807 (2015).

118. Mei, Y. et al. Adult restoration of Shank3 expression rescues selective autisticlike phenotypes. Nature 530, 481-484 (2016).

119. Wang, W. et al. Treating a novel plasticity defect rescues episodic memory in Fragile X model mice. Mol. Psychiatry 8, 1798-1806 (2018).

120. Nakai, N., Takumi, T., Nakai, J. \& Sato, M. Common defects of spine dynamics and circuit function in neurodevelopmental disorders: A systematic review of findings from in vivo optical imaging of mouse models. Front Neurosci. 12, 412 (2018).

121. Lauterborn, J. C. et al. Brain-derived neurotrophic factor rescues synaptic plasticity in a mouse model of fragile $X$ syndrome. J. Neurosci. 27, 10685-10694 (2007).

122. Chen, L. Y. et al. Physiological activation of synaptic Rac>PAK (p-21 activated kinase) signaling is defective in a mouse model of fragile $X$ syndrome. $J$. Neurosci. 30, 10977-10984 (2010).

123. Kleschevnikov, A. M. et al. Hippocampal long-term potentiation suppressed by increased inhibition in the Ts65Dn mouse, a genetic model of Down syndrome. J. Neurosci. 24, 8153-8160 (2004).

124. Belichenko, P. V. et al. Excitatory-inhibitory relationship in the fascia dentata in the Ts65Dn mouse model of Down syndrome. J. Comp. Neurol. 512, 453-466 (2009).

125. Roncacé, V. et al. Neuroanatomical alterations and synaptic plasticity impairment in the perirhinal cortex of theTs65Dn mouse model of Down syndrome. Neurobiol. Dis. 106, 89-100 (2017).

126. Sun J. et al. UBE3A-mediated p18/LAMTOR1 ubiquitination and degradation regulate $\mathrm{mTORC1}$ activity and synaptic plasticity. Elife. https://doi.org/10.7554/ elife.37993 (2018).

127. Cao, C. et al. Impairment of TrkB-PSD-95 signaling in Angelman syndrome. PLoS Biol. 11, e1001478 (2013).

128. Gocel, J. \& Larson, J. Synaptic NMDA receptor-mediated currents in anterior piriform cortex are reduced in the adult fragile X mouse. Neuroscience 221, 170-181 (2012).

129. Bostrom, C. A. et al. Rescue of NMDAR-dependent synaptic plasticity in Fmr1 knock-out mice. Cereb. Cortex 25, 271-279 (2015).

130. Silverman, J. L. et al. Negative allosteric modulation of the mGluR5 receptor reduces repetitive behaviors and rescues social deficits in mouse models of autism. Sci. Transl. Med. 4, 131 ra51 (2012).

131. Darnell, J. C. \& Klann, E. The translation of translational control by FMRP therapeutic targets for FXS. Nat. Neurosci. 16, 1530-1536 (2013).

132. Gardiner, K. J. Pharmacological approaches to improving cognitive function in Down syndrome: current status and considerations. Drug Des. Devel Ther. 9, 103-125 (2014).

133. Lynch, G. \& Gall, C. M. Mechanism based approaches for rescuing and enhancing cognition. Front. Neurosci. 7, 143 (2013).

134. Bartesaghi, R. et al. New perspectives for the rescue of cognitive disability in Down syndrome. J. Neurosci. 35, 13843-13852 (2015).

135. Silverman, J. L. \& Crawley, J. N. The promising trajectory of autism therapeutics discovery. Drug Disco. Today 19, 838-844 (2014).

136. Lozano, R., Azarang, A., Wilaisakditipakorn, T. \& Hagerman, R. J. Fragile X syndrome: A review of clinical management. Intractable Rare Dis. Res. 5, 145-157 (2016).

137. Budimirovic, D. B. et al. Updated report on tools to measure outcomes of clinical trials in fragile X syndrome. J. Neurodev. Disord. 9, 14 (2017).

138. Faundez, V. et al. Down syndrome and other genetic developmental disorders ECNP network. Translating molecular advances in Down syndrome and Fragile $X$ syndrome into therapies. Eur. Neuropsychopharmacol. 28, 675-690 (2018). 
139. Stoppel, L. J. et al. R-baclofen reverses cognitive deficits and improves social interactions in two lines of 16p11.2 deletion mice. Neuropsychopharmacology 43, 513-524 (2018)

140. Berry-Kravis, E. M. et al. Drug development for neurodevelopmental disorders: lessons learned from fragile X syndrome. Nat. Rev. Drug Discov. 17, 280-299 (2018)

141. Caston, J., Jones, N. \& Stelz, T. Role of preoperative and postoperative sensorimotor training on restoration of the equilibrium behavior in adult mice following cerebellectomy. Neurobiol. Learn Mem. 64, 195-202 (1995).

142. Lalonde, R., Filali, M., Bensoula, A. N. \& Lestienne, F. Sensorimotor learning in three cerebellar mutant mice. Neurobiol. Learn Mem. 65, 113-120 (1996).

143. Goddyn, H., Leo, S., Meert, T. \& D'Hooge, R. Differences in behavioural test battery performance between mice with hippocampal and cerebellar lesions. Behav. Brain Res. 173, 138-147 (2006).

144. Schenk, F. \& Morris, R. G. Dissociation between components of spatial memory in rats after recovery from the effects of retrohippocampal lesions. Exp. Brain Res. 58, 11-28 (1985).

145. Eichenbaum, H., Stewart, C. \& Morris, R. G. Hippocampal representation in place learning. J. Neurosci. 10, 3531-3542 (1990).

146. Moser, M. B., Moser, E. I., Forrest, E., Andersen, P. \& Morris, R. G. Spatial learning with a minislab in the dorsal hippocampus. Proc. Natl. Acad. Sci. USA 92 9697-9701 (1995).

147. Berger-Sweeney, J. et al. Selective immunolesions of cholinergic neurons in mice: effects on neuroanatomy, neurochemistry, and behavior. J. Neurosci. 21, 8164-8173 (2001)

148. Mele, A. et al. Nucleus accumbens dopamine receptors in the consolidation of spatial memory. Behav. Pharmacol. 15, 423-431 (2004).

149. Vieira, P. A. \& Korzus, E. CBP-Dependent memory consolidation in the prefrontal cortex supports object-location learning. Hippocampus 5, 1532-1540 (2015)

150. Chen, T. W., Li, N., Daie, K. \& Svoboda, K. A map of anticipatory activity in mouse motor cortex. Neuron 94, 866-879 (2017).

151. Winters, B. D. \& Bussey, T. J. Transient inactivation of perirhinal cortex disrupts encoding, retrieval, and consolidation of object recognition memory. J. Neuroscience 25, 52-61 (2005)

152. Weible, A. P., Rowland, D. C., Pang, R. \& Kentros, C. Neural correlates of nove object and novel location recognition behavior in the mouse anterior cingulate cortex. J. Neurophysiol. 102, 2055-2068 (2009).

153. Yamazaki, T., Nagao, S., Lennon, W. \& Tanaka, S. Modeling memory consolidation during posttraining periods in cerebellovestibular learning. Proc Natl. Acad. Sci. USA 112, 3541-3546 (2015).
154. Litrownik, A. J., Franzini, L. R. \& Turner, G. L. Acquisition of concepts by TMR children as a function of type of modeling, rule verbalization, and observer gender. Am. J. Ment. Defic. 80, 620-628 (1976).

155. Chasey, W. C. Distribution of practice effects on learning retention and relearning by retarded boys. Percept. Mot. Skills 43, 159-164 (1976).

156. Heitman, R. J. \& Gilley, W. F. Effects of blocked versus random practice by mentally retarded subjects on learning a novel skill. Percept. Mot. Skills 69 , 443-447 (1989).

157. Wek, S. R. \& Husak, W. S. Distributed and massed practice effects on motor performance and learning of autistic children. Percept. Mot. Skills 68, 107-113 (1989).

158. Rider, R. A. Abdulahad DT. Effects of massed versus distributed practice on gross and fine motor proficiency of educable mentally handicapped adolescents. Percept. Mot. Skills. 73, 219-224 (1991).

159. Haq, S. S. et al. Comparing the effects of massed and distributed practice on skill acquisition for children with autism. J. Appl Behav. Anal. 48, 454-459 (2015).

160. Majdalany, L. M., Wilder, D. A., Greif, A., Mathisen, D. \& Saini, V. Comparing massed-trial instruction, distributed-trial instruction, and task interspersal to teach tacts to children with autism spectrum disorders. J. Appl. Behav. Anal. 47, 657-662 (2014).

161. Ashby, S. A., Channell, M. M. \& Abbeduto, L. Inferential language use by youth with Down syndrome during narration. Res Dev. Disabil. 71, 98-108 (2017).

162. McDuffie, A. et al. Distance delivery of a spoken language intervention for school-aged and adolescent boys with fragile X syndrome. Dev. Neurorehabil. 21, 48-6 (2018).

163. Hamner, T., Udhnani, M. D., Osipowicz, K. Z. \& Lee, N. R. Pediatric brain development in Down syndrome: A field in its infancy. J. Int Neuropsychol. Soc. 23, 1-11 (2018).

164. Hagerman, R. J. et al. Fragile X syndrome. Nat. Rev. Dis. Prim. 3, 17065 (2017)

165. Margolis, S. S., Sell, G. L., Zbinden, M. A. \& Bird, L. M. Angelman Syndrome Neurotherapeutics 12, 641-650 (2015).

166. Williams, C. A. et al. Angelman syndrome 2005: updated consensus for diagnostic criteria. Am. J. Med. Genet. A. 140, 413-418 (2006).

167. Vismara, L. A. \& Rogers, S. J. Behavioral treatments in autism spectrum disorder: what do we know? Annu Rev. Clin. Psychol. 6, 447-468 (2010).

168. Lord, C. \& Bishop, S. L. Recent advances in autism research as reflected in DSM-5 criteria for autism spectrum disorder. Annu Rev. Clin. Psychol. 11, 53-70 (2015). 